\title{
Modulation of GABAA Receptor Signaling Increases Neurogenesis and Suppresses Anxiety through NFATc4
}

\author{
Giorgia Quadrato, ${ }^{1 \star}$ Mohamed Y. Elnaggar, ${ }^{1,2 \star}$ Ceren Duman, ${ }^{1,2}$ Andrea Sabino, ${ }^{1}$ Kirsi Forsberg, ${ }^{1}$ \\ and Simone Di Giovanni ${ }^{1,3}$ \\ ${ }^{1}$ Laboratory for NeuroRegeneration and Repair, Center for Neurology, Hertie Institute for Clinical Brain Research, University of Tuebingen, 72076 \\ Tuebingen, Germany, ${ }^{2}$ Graduate School for Cellular and Molecular Neuroscience, University of Tuebingen, 72074 Tuebingen, Germany, and ${ }^{3}$ Molecular \\ Neuroregeneration, Division of Brain Sciences, Department of Medicine, Imperial College London, London W12 ONN, United Kingdom
}

Correlative evidence suggests that GABAergic signaling plays an important role in the regulation of activity-dependent hippocampal neurogenesis and emotional behavior in adult mice. However, whether these are causally linked at the molecular level remains elusive. Nuclear factor of activated T cell (NFAT) proteins are activity-dependent transcription factors that respond to environmental stimuli in different cell types, including hippocampal newborn neurons. Here, we identify NFATc4 as a key activity-dependent transcriptional regulator of GABA signaling in hippocampal progenitor cells via an unbiased high-throughput genome-wide study. Next, we demonstrate that $\mathrm{GABA}_{\mathrm{A}}$ receptor $\left(\mathrm{GABA}_{\mathrm{A}} \mathrm{R}\right)$ signaling modulates hippocampal neurogenesis through NFATc4 activity, which in turn regulates GABRA2 and GABRA4 subunit expression via binding to specific promoter responsive elements, as assessed by ChIP and luciferase assays. Furthermore, we show that selective pharmacological enhancement of $\mathrm{GABA}_{\mathrm{A}} \mathrm{R}$ activity promotes hippocampal neurogenesis via the calcineurin/NFATc4 axis. Importantly, the NFATc4-dependent increase in hippocampal neurogenesis after $\mathrm{GABA}_{\mathrm{A}} \mathrm{R}$ stimulation is required for the suppression of the anxiety response in mice. Together, these data provide a novel molecular insight into the regulation of the anxiety response in mice, suggesting that the $\mathrm{GABA}_{\mathrm{A}} \mathrm{R} / \mathrm{NFATc} 4$ axis is a druggable target for the therapy of emotional disorders.

Key words: adult hippocampal neurogenesis; anxiety; GABAergic signaling; NFATc4

\section{Introduction}

Functional and neuroimaging studies have correlated hippocampal activity, integrity, and size with emotional behavior in both humans and animals (Gilbertson et al., 2002; Campbell et al., 2004; Kitayama et al., 2005; Irle et al., 2010; Kheirbek et al., 2013). Specifically, it has been shown that impaired adult hippocampal neurogenesis is implicated in the pathogenesis of a number of cognitive and psychiatric disorders (Snyder et al., 2011; Kheirbek et al., 2012; Petrik et al., 2012; Sahay et al., 2011) and that the effective treatment of anxiety/depression-related behavior in rodents requires intact hippocampal neurogenesis (Santarelli et al., 2003; David et al., 2009; Surget et al., 2011). Importantly, the

Received Jan. 6, 2014; revised April 11, 2014; accepted May 9, 2014.

Author contributions: G.O. and S.D.G. designed research; G.O., M.Y.E., C.D., and A.S. performed research; K.F. contributed unpublished reagents/analytic tools; G.Q., M.Y.E., and C.D. analyzed data; G.Q. and S.D.G. wrote the paper.

This work was supported by the Hertie Foundation and the Deutsche Forschungsgemeinschaft (S.D.G.) and the Fortune Program of the University of Tübingen (G.Q.). We thank Tuan Nguyen for important conceptual feedback, Alexandra Lepier for the design and the production of the retroviruses used, Maria Mina for technical help, Jeffery D. Molkentin for providing the NFATc4-null mice, and Verdon Taylor for providing the Hes5-GFP mice.

The authors declare no competing financial interests.

*G.Q. and M.Y.E. contributed equally to this work.

Correspondence should be addressed to either of the following: Giorgia Quadrato, Molecular Neuroregeneration, Division of Brain Sciences, Department of Medicine, Imperial College London, London W12 0NN, United Kingdom, E-mail: giorgia.quadrato@uni-tuebingen.de; or Simone Di Giovanni, Molecular Neuroregeneration, Division of Brain Sciences, Department of Medicine, Imperial college London, London W12 ONN, United Kingdom, E-mail: s.digiovanni@imperial.ac.uk.

DOI:10.1523/JNEUROSCI.0047-14.2014

Copyright $\odot 2014$ the authors $\quad 0270-6474 / 14 / 348630-16 \$ 15.00 / 0$ finding that adult neurogenesis occurs in the adult human hippocampus (Spalding et al., 2013) at rates comparable to those described in mice (Kempermann et al., 1997) suggests that it might as well have a functional role in the regulation of cognitive and emotional human behavior (Kheirbek and Hen, 2013). Therefore, the elucidation of the molecular link between adult hippocampal neurogenesis and emotional responses in mice might be critical for the development of more effective treatments for clinical anxiety disorders. GABA signaling, which is one of the most important regulator of activity-dependent hippocampal neurogenesis during adulthood (Ge et al., 2007), is known to play a central role in the pathophysiology of anxiety disorders (Lydiard, 2003; Nemeroff, 2003). However, it is not clear whether GABAergic modulation of adult neurogenesis affects anxiety levels in mice and which molecular players causally regulate these two events. It has been shown that GABAergic excitation shapes neural maturation and differentiation specifically by the enhancement of $\mathrm{GABA}_{\mathrm{A}}$ receptor $\left(\mathrm{GABA}_{\mathrm{A}} \mathrm{R}\right)$ expression and activity in neural progenitor cells (Tozuka et al., 2005; Ge et al., 2006). GABA ${ }_{\mathrm{A}}$ Rs are hetero-oligomeric complexes composed of five subunits that are expressed and assembled in a cell type- and spatiotemporal-specific fashion in the brain. The composition of the $\mathrm{GABA}_{\mathrm{A}} \mathrm{R}$ subunits determines their functional and pharmacological properties. Specifically, the functional expression of the $\alpha 2$ (GABRA2) and $\alpha 4$ (GABRA4) GABA $\mathrm{A}_{\mathrm{A}} \mathrm{R}$ subunits in neural progenitor cells controls adult neurogenesis in the mouse DG (Duveau et al., 2011). Vertebrate GABA R $_{\mathrm{A}}$ subunits 
are organized in several gene clusters localized on different chromosomes originated by gene duplication. Interestingly, GABRA2 and GABRA4 subunits belong to the same genomic cluster, and this genomic organization might have been conserved to facilitate transcriptional coregulation (Joyce, 2007). However the transcriptional machinery involved in the coordinate regulation of $\mathrm{GABA}_{\mathrm{A}} \mathrm{R}$ subunits in hippocampal neural progenitor cells still needs to be investigated.

Here, we demonstrate with several lines of evidence that $\mathrm{GABA}_{\mathrm{A}} \mathrm{R}$ signaling operates through NFATc4 activity, an activity-dependent transcription factor expressed in hippocampal adult-born neurons (Quadrato et al., 2012). NFATc4 modulates hippocampal neurogenesis by direct transcriptional coregulation of GABRA2 and GABRA4 subunit expression by binding to specific responsive elements on their promoters. Furthermore, we show that selective pharmacological enhancement of $\mathrm{GABA}_{\mathrm{A}} \mathrm{R}$ activity promotes hippocampal neuronal differentiation via calcineurin/NFATc4, which in turn modulates innate anxiety levels in adult mice. These findings provide a causal link between modulation of hippocampal neurogenesis and changes in anxiety levels by proposing NFATc4 as a key transcriptional regulator in GABAergic signaling and suggest that NFATc4/ GABAergic signaling is a druggable target for the therapy of emotional disorders.

\section{Materials and Methods}

Animals. Wild-type (WT) and nuclear factor of activated T cell-knockout (NFATc4 ${ }^{-\prime-}$ ) mice (Wilkins et al., 2002) were housed under standard conditions with food and water available ad libitum and kept on a 12 $\mathrm{h}$ dark/light cycle. Mice were maintained on a mixed C57BL/6 and 129 S7 genetic background. Adult littermate male mice (between 2 and 5 months of age) were used in the study. All experiments were performed according to National Institutes of Health and European Union Animal Care standards and local animal care guidelines at the University of Tübingen.

Cell culture of adult hippocampal neurospheres and pharmacological treatment. For in vitro experiments, we used adult hippocampal neural stem cell cultures isolated after selective microdissection of the DG of 3to 4-month-old WT, NFATc4 ${ }^{-1-}$ and Hes5-GFP mice (kindly provided by Dr. Verdon Taylor). Cultures were maintained following the same procedures described previously (Quadrato et al., 2012). All neurospheres were cultured in serum-free DMEM/F-12 medium (1:1; Invitrogen) containing the following: $200 \mathrm{mM} \mathrm{L}$-glutamine (Invitrogen), $100 \mathrm{U}$ penicillin/streptomycin (Invitrogen), 2\% B27 supplement without vitamin A (Invitrogen), $20 \mathrm{ng} / \mathrm{ml}$ epidermal growth factor (Millipore), 20 $\mathrm{ng} / \mathrm{ml}$ basic fibroblast growth factor (bFGF; Millipore), and $2.5 \mu \mathrm{g} / \mathrm{ml}$ heparin (Sigma-Aldrich). For neuronal differentiation, neural progenitor cells were transferred to differentiation medium [DMEM/F-12 medium containing the following: $100 \mathrm{U}$ penicillin/streptomycin, $200 \mathrm{~mm}$ L-glutamine, 2\% B27 supplement with vitamin A (Life Technologies), 0.1 $\mu \mathrm{M}$ retinoic acid (Sigma-Aldrich), and $0.5 \mu \mathrm{M}$ forskolin (Calbiochem)] with $20 \mathrm{ng} / \mathrm{ml} \mathrm{bFGF}$ overnight, and then switched to differentiation medium without bFGF for up to $5 \mathrm{~d}$. In differentiating conditions, the following drugs were administrated in culture medium: $100 \mathrm{ng} / \mathrm{ml}$ cyclosporin A (CsA; LC Laboratories), $100 \mathrm{ng} / \mathrm{ml}$ BDNF (R\&D Systems), or 10 $\mu \mathrm{M}$ muscimol (Sigma-Aldrich). WT and NFATc4 ${ }^{-1-}$ neurospheres (NSPs) were infected with control-dsred and NFATc4-dsred expressing retroviral constructs and seeded at a density of $1 \times 10^{5}$ cells into 24-well tissue culture plates in differentiation medium. Muscimol was added to the medium and cells were incubated for 1,2 or $5 \mathrm{~d}$.

Immunocytochemistry. Immunocytochemistry was performed as described previously (Quadrato et al., 2012). Primary antibodies used were as follows: monoclonal rabbit anti-NFATc4 (1:100; Cell Signaling Technology), polyclonal rabbit anti-GABAR $\alpha 4$ (1:200; Abcam), polyclonal goat anti-GABAR $\alpha 4$ (1:100; Santa Cruz Biotechnology), polyclonal rabbit anti-GABAR $\alpha 2$ (1:200; Alomone labs), polyclonal goat antiGABAR $\alpha 2$ (1:100; Santa Cruz Biotechnology), monoclonal mouse anti- nestin (1:200; Millipore), monoclonal anti-MAP2 (1:200; Abcam), polyclonal rabbit anti-cleaved caspase-3 (1:500; Cell Signaling Technology), monoclonal mouse anti-SOX2 (1:100; Abcam), polyclonal rabbit anti-SOX2 (1:400; Abcam), monoclonal mouse anti-SOX2 (1:400; Abcam), and polyclonal chicken anti-GFP (1:500; Abcam). The secondary antibodies used were as follows: Alexa Fluor goat anti-mouse 488, goat anti-rabbit 546, goat anti-rat 647 , donkey anti-goat 488 , donkey antirabbit 568, and donkey anti-mouse 647 (1:1500; Invitrogen). Cell nuclei were stained with Hoechst staining (1:5000; Invitrogen) and the glass coverslips were mounted using DAKO fluorescence mounting medium. Cells were imaged using an Axiovert 200M (Zeiss) microscope with AxioVision software (version 4.8.1; Zeiss).

Fluorescence intensity threshold analysis. Quantification of the number of viable cells with a staining intensity for anti-GABRA2 or anti-GABRA4 antibodies above the "intermode" threshold was made using ImageJ software. Approximately 100 cells were counted for each coverslip. Cells above intensity threshold were divided by the total number of viable cells to calculate their percentage. Viability of cells was determined using DAPI staining.

Microarray analysis. Hippocampal NSP cultures derived from WT and NFATc $4^{-1-}$ mice were differentiated for $1 \mathrm{~d}$ with BDNF added to the medium. Total RNA was isolated from the cells using PureLink RNA micro kit (Invitrogen) according to manufacturer's instructions. Whole transcriptome analysis was performed using an Affymetrix Mouse Gene 1.1 ST array on the Affymetrix GeneTitan System. For this purpose, triplicates of each sample were analyzed.

RNA quality was evaluated on Agilent 2100 Bioanalyzer with RNA integrity numbers (RINs) ranging from 8 to 10 ; all RINs $>8$ were considered optimal for downstream applications.

Double-stranded cDNA was synthesized from $100 \mathrm{ng}$ of total RNA and subsequently linearly amplified and biotinylated using the GeneChip WT cDNA Synthesis and Amplification Kit (Affymetrix) according to the manufacturer's instructions. Fifteen micrograms of labeled and fragmented cDNA was hybridized to GeneChip Mouse Gene 1.1 ST arrays (Affymetrix). After hybridization, the arrays were washed and stained in a Fluidics Station 450 (Affymetrix) with the recommended washing procedure. Biotinylated cDNA bound to target molecules was detected with streptavidin-coupled phycoerythrin, biotinylated anti-streptavidin IgG antibodies and again streptavidin-coupled phycoerythrin according to the protocol. Arrays were scanned using the Affymetrix GeneTitan scanner and AGCC 3.0 software. Scanned images were subjected to visual inspection to check for hybridization artifacts and proper grid alignment and analyzed with Expression Console 1.0 (Affymetrix) to generate report files for quality control. Normalization of raw data was performed with Partek software, applying a robust multichip average algorithm. Hierachical cluster analysis was performed with average linkage for genes. Heat maps were generated with Bioconductor package gplots. Gene ontology classification and pathway analyses was performed using Ingenuity Pathway Analysis software (http://www.ingenuity.com/).

Quantitative PCR. Cells were differentiated and total RNA was extracted using PureLink RNA micro kit according to the manufacturer's protocol, followed by cDNA synthesis from $1 \mu \mathrm{g}$ of RNA using oligodT (SuperScript II Reverse Transcriptase; Invitrogen). Quantitative PCR (qPCR) was performed using 7500 Fast Real-Time PCR System software version 2.0.4 (Applied Biosystems). The reaction mix was composed of SYBR Green Mix (1:2; Invitrogen), 100 nM primers (GABRA4 forward: ACGAGAAATTGTGCCCGGAA, GABRA4 reverse: ACATCAGAAA CGGGCCCAAA, GABRA2 forward: GCTCGAAATTCCCTCCCGAA, GABRA2 reverse: ACTACACTCTTCCCGTCCCA, GABBR1 forward: CAGTCGCTGTGTCCGAATCT, GABBR1 reverse: GTCGGGGTCA CATCGGAAAT, GABRB1 forward: CGCCGACTAAGTTGCATTCC, GABRB1 reverse: ACCATAGCAACCATCACGGG, GABBR2 forward: GTGAATCAGGGGCATTCTGCT, GABBR2 reverse: AGCCTCCTGA TGGACCACTT) and $1 \mu \mathrm{l}$ of template (1:5 dilution of reverse transcription sample) in a total volume of $20 \mu \mathrm{l}$. All reactions were conducted in the same conditions $\left(50^{\circ} \mathrm{C}, 20 \mathrm{~s} ; 95^{\circ} \mathrm{C}, 15 \mathrm{~min}\right.$ for 1 cycle; $95^{\circ} \mathrm{C}, 15 \mathrm{~s} ; 60^{\circ} \mathrm{C}$, $30 \mathrm{~s} ; 72^{\circ} \mathrm{C}, 1 \mathrm{~min}$ for 40 cycles.). After that, the melting curve analysis was applied $\left(95^{\circ} \mathrm{C}, 15 \mathrm{~s}, 60^{\circ} \mathrm{C}, 1 \mathrm{~min}, 95^{\circ} \mathrm{C} .30 \mathrm{~s}, 60^{\circ} \mathrm{C}, 15 \mathrm{~s}\right)$. Samples were run in technical and biological triplicates and normalized to endogenous 
GAPDH expression levels. $\Delta \Delta \mathrm{CT}$ analysis method was applied for the fold change calculations of the mRNA expression levels.

ChIP assay. The ChIP assay was performed as described by Floriddia et al. (2011). Briefly, $1.5 \times 10^{5}$ neural progenitor cells were differentiated for $1 \mathrm{~d}$ in the following conditions: WT BDNF-treated, NFATc4 ${ }^{-1-}$ BDNF-treated, WT CsA-treated, and NFATc4 ${ }^{-1-}$ CSA-treated. Cells were fixed using formaldehyde solution at a final concentration of $1 \%$ for $30 \mathrm{~min}$ at $37^{\circ} \mathrm{C}$. After cell lysis ( $0.5 \%$ SDS, $100 \mathrm{~mm} \mathrm{NaCl}, 50 \mathrm{~mm}$ Tris $\mathrm{HCl}$, pH 8.0, 5 mm EDTA), extracts were sonicated to shear DNA into 200$1000 \mathrm{bp}$ lengths. Sheared chromatin solutions were incubated overnight at $4^{\circ} \mathrm{C}$ with rabbit monoclonal anti-NFATc4 antibody (Cell Signaling Technology) and normal rabbit IgG antibody (Cell Signaling Technology) with rotation. After incubation, the samples were immunoprecipitated with ChIP Grade Protein G Magnetic Beads (Cell Signaling Technology) and incubated for $2 \mathrm{~h}$ at $4^{\circ} \mathrm{C}$ with rotation. The precipitated complexes were washed repeatedly and incubated for $30 \mathrm{~min}$ at $65^{\circ} \mathrm{C}$ in parallel with input samples to elute the chromatin from the beads. Later, the beads were removed and samples were incubated $2 \mathrm{~h}$ at $65^{\circ} \mathrm{C}$ to reverse the crosslinks. DNA was isolated by phenol/chloroform extraction followed later by ethanol precipitation with sodium acetate. qPCR amplification of isolated DNA samples was performed as described previously using the following primers: GABRA4 forward: AGTTTGTCACTGTCACTTTGGT, GABRA4 reverse: TCCTTTCCCTTAGAAAGCATCAGA, GABRA2 forward: ACCATAGGTCAGGCTCTCCA, GABRA2 reverse: TCCTGACAT TGTCCAGTCTCC, GABRA2.1 forward: ACCACAGGTGTCCAACAT CAA, GABRA2.1 reverse: ATTTGAGAGGCTTCGTCAGCA. For ChIP primer design, potential NFAT-binding sites within the predicted gabra2 and gabra4 promoter regions were identified using MatInspector algorithm in Genomatix software (http://www.genomatix.de/). Each immunoprecipitation sample was normalized to input and IgG immunoprecipitation fractions for fold enrichment calculations using Ct values.

Dual luciferase reporter assay. Hippocampal progenitor cells derived from WT and NFATc4 ${ }^{-1-}$ animals were seeded at a density of $1 \times 10^{4}$ cells in 96-well plates under the conditions of WT BDNF-treated, WT vehicle-treated, NFATc $4^{-1-}$ BDNF-treated, NFATc $4^{-1-}$ vehicle-treated, and WT CsA-treated. Cells were cotransfected with one of the LightSwitch GoClone reporter plasmids in which the luciferase expression is dependent on gabra4 or gabra2 promoter (SwitchGear Genomics) and with the Cypridina TK control construct using FuGENE HD transfection reagent. Reporter assays were performed at $24 \mathrm{~h}$ after transfection with LightSwitch Dual Assay system (SwitchGear Genomics) and plates were read using a luminescence plate reader (Mithras LB940 96-well plate reader; Berthold Technologies). All transfections were conducted in triplicate.

Viral vectors and stereotaxic injection. For NFATc4 overexpression, full-length human NFATc4 cDNA (Addgene) was subcloned into a retrovial backbone containing a CAG promoter followed by internal ribosome entry site (IRES)-dsredExpress2. As a control, a CAG-IRESdsredExpress 2 vector was used. For stereotaxic injections, anesthetized (90 mg/kg ketamine and $10 \mathrm{mg} / \mathrm{kg}$ xylazine) mice were mounted on a stereotaxic alignment system (Steolting). Mice were injected unilaterally at two sites of the DG with $0.75 \mu$ l of retroviral suspension (1:5 dilution in PBS) as described previously (Gu et al., 2011). Coordinates from bregma of the first site were as follows: $-2 \mathrm{~mm}$ anteroposterior, \pm 1.6 $\mathrm{mm}$ lateral, $2.5 \mathrm{~mm}$ ventral, and for the second site, $-3 \mathrm{~mm}$ anterioposterior, $\pm 2.6 \mathrm{~mm}$ lateral, $3.2 \mathrm{~mm}$ ventral. Animals were returned to the standard housing conditions until the desired time points after injection.

Drug treatment and BrdU labeling. Mice were injected intraperitoneally once every $24 \mathrm{~h}$ with muscimol (M1523; Sigma-Aldrich) at $4 \mathrm{mg} / \mathrm{kg}$ body weight in $0.05 \mathrm{M} \mathrm{HCl}$ for $24 \mathrm{~d}$. For the first $3 \mathrm{~d}$ of treatment, animals were also injected every $12 \mathrm{~h}$ with BrdU (B5002; Sigma-Aldrich) at 75 $\mathrm{mg} / \mathrm{kg}$ body weight in saline. For suppression of neurogenesis, temozolomide (T2577; Sigma-Aldrich) was injected at $25 \mathrm{mg} / \mathrm{kg}$ body weight in DMSO on the first $3 \mathrm{~d}$ of a week for 4 weeks, as described previously (Garthe et al., 2009). For the control group, DMSO was injected following the same paradigm.

Tissue preparation and immunohistochemistry. Mice were perfused transcardially with $0.1 \mathrm{~m}$ PBS solution, $\mathrm{pH} 7.4$, followed by $4 \% \mathrm{PFA}, \mathrm{pH}$ 7.4. Brains were dissected and postfixed overnight at $4^{\circ} \mathrm{C}$ and were then immersed in $30 \%$ sucrose for cryoprotection. Free-floating $40 \mu \mathrm{m}$ coronal sections spanning the whole hippocampus were cut using a Leica cryostat, collected in cryoprotectant solution, and stored at $-20^{\circ} \mathrm{C}$ until further use. Primary antibodies used were rat monoclonal antibody antiBrdU (1:100; Novus Biologicals), mouse monoclonal anti-BrdU (1:400, Cell Signaling Technology), rabbit polyclonal anti-calbindin (anti-CB, 1:3000; Swant), mouse monoclonal anti-RFP (1:600; Abcam), rat monoclonal anti-GFAP (1:400; Invitrogen), mouse monoclonal anti-nestin (1:100; Millipore), goat polyclonal anti-doublecortin (1:200; Santa Cruz Biotechnology). The secondary antibodies used were as follows: Alexa Fluor goat anti-mouse 488 , goat anti-rabbit 568 , goat anti-rat 488 , donkey anti-rabbit 568 , donkey anti-mouse 488 , goat anti-rabbit 647 , and goat anti-rat 568 (Invitrogen), biotinylated anti-mouse (1:200; Vector Laboratories), and streptavidin 488 (1:400; Invitrogen).

For BrdU detection, DNA was denatured by exposing sections to $2 \mathrm{~N} \mathrm{HCl}$ for $35 \mathrm{~min}$ at $37^{\circ} \mathrm{C}$, followed by two washes in $0.1 \mathrm{M}$ sodium tetraborate buffer, $\mathrm{pH} 8.5$, for $10 \mathrm{~min}$ at room temperature. For NFATc4 detection, antigen retrieval [ $10 \mathrm{~mm}$ citric acid (Roth), 2 mм EDTA (Sigma-Aldrich), and $0.05 \%$ Tween 20 (Roth), pH 6.2] was performed.

Cell counting and stereology. For quantification of the percentage of RFP and CB double-positive cells in adult-born neurons, the percentage of $\mathrm{RFP}^{+} / \mathrm{CB}^{+}$cells over the total number of $\mathrm{RFP}^{+}$cells was assessed in the DG of all the groups. The total number of $\mathrm{BrdU}^{+}$cells, the total number of $\mathrm{BrdU}^{+} / \mathrm{CB}^{+}$cells, and the total number of $\mathrm{BrdU}^{+} / \mathrm{GFAP}^{+}$ cells were assessed in WT and NFATc4 ${ }^{-1-}$ mice treated with either muscimol or vehicle. The number of positive cells was determined in every tenth section in a series of $40 \mu \mathrm{m}$ coronal sections spanning the complete DG using the optical dissector principle. Fluorescent signals were detected using confocal laser microscopy (LSM 510 Axiovert 200M; Zeiss). Positive cells were counted using a $63 \times$ oil objective and cells located in the upper most focal plane were not counted.

Elevated plus maze. To test anxiety-related behavior, WT and NFATc $4^{-1-}$ mice between 2 and 5 months of age were tested using the elevated plus maze (EPM). Mice were placed for 5 minutes on an elevated maze composed of four arms, two with black high walls and two without walls. Each arm was $76.5 \mathrm{~cm}$ long and $74 \mathrm{~cm}$ elevated above the ground. Mice were placed in the testing room $1 \mathrm{~h}$ before test under dim light to allow them to habituate. The sessions were videotaped and the total distance and the distance traveled in closed and open arms were recorded using the Ethovision video-tracking system (Noldus).

Statistical analysis. All numerical analyses were performed using Excel software (Microsoft). To compare the averages between two groups for in vitro, in vivo, and ex vivo experiments, unpaired two-tailed Student's $t$ test was used. For the EPM test, latencies were analyzed using one-way ANOVA (with genotype as independent factor and time spent in open arm as repeated-measure factor) followed by Bonferroni's post hoc test for group comparison. Differences were considered significant at $p<0.05$.

\section{Results}

Identification of GABAergic signaling as a target of NFATc4 in adult hippocampal progenitor cells via genome-wide transcriptome analysis

After a search for activity-dependent molecular pathways in adult mouse hippocampal neural precursor cells, we identified GABAergic signaling as a central pathway targeted by NFATc4. This was achieved by carrying out an unbiased high throughput genome wide transcriptome analysis in WT versus NFATc4 ${ }^{-1-}$ differentiating neural precursor cells (NPCs) derived from the adult DG. The significance of gene expression changes was calculated using a $t$ test without multiple testing corrections (Partek), selecting all transcripts with a minimum of 1.5 -fold change in the expression level and $p<0.05$ (the entire dataset is available upon request). Signal intensities were scaled and centered and the distance between two expression profiles was calculated using the Euclidean distance measure, which clearly shows changes between WT and NFATc4 ${ }^{-1-}$ gene expression profiles (Fig. 1A). Indeed, gene ontology classification and pathway analyses 

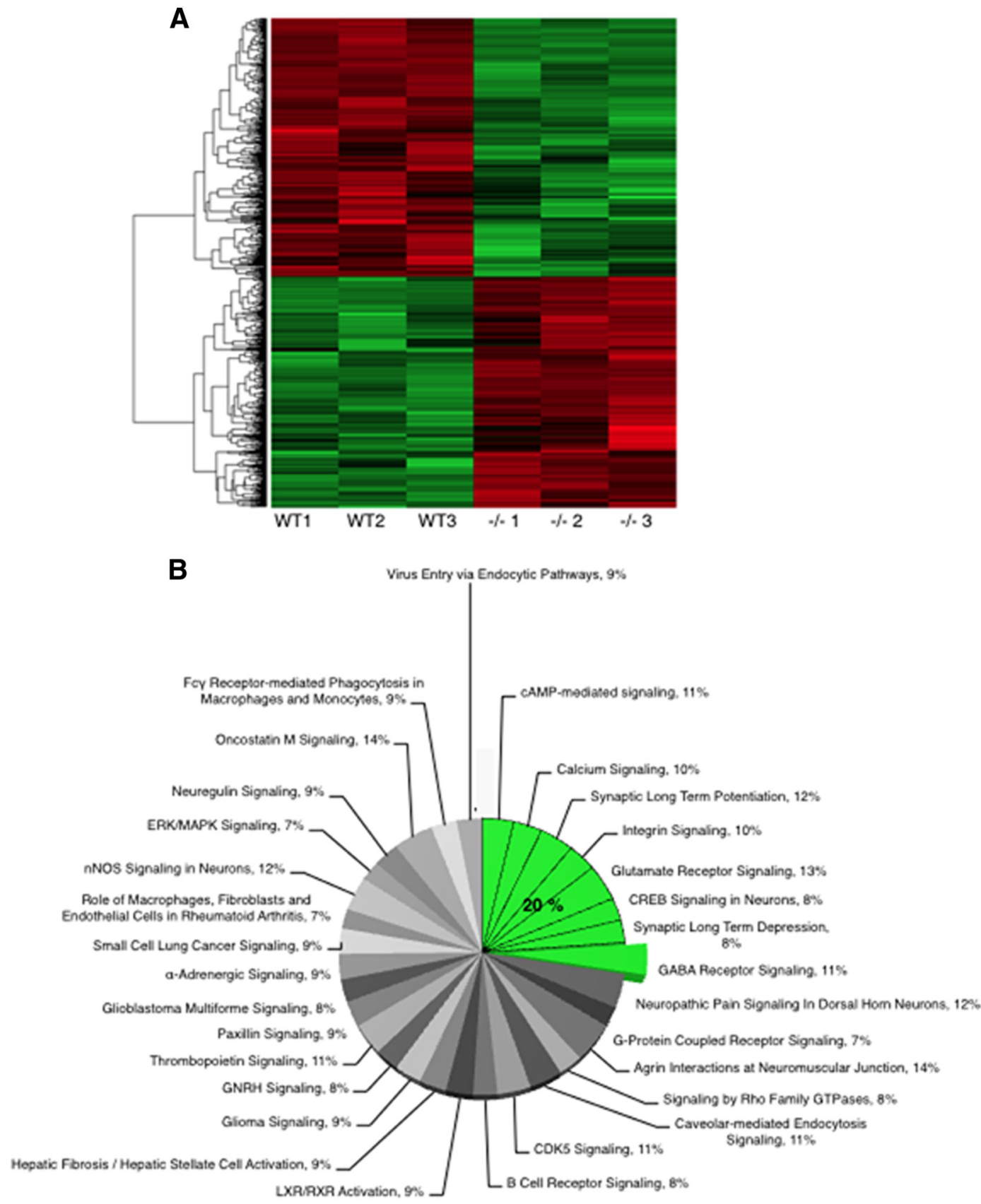

C

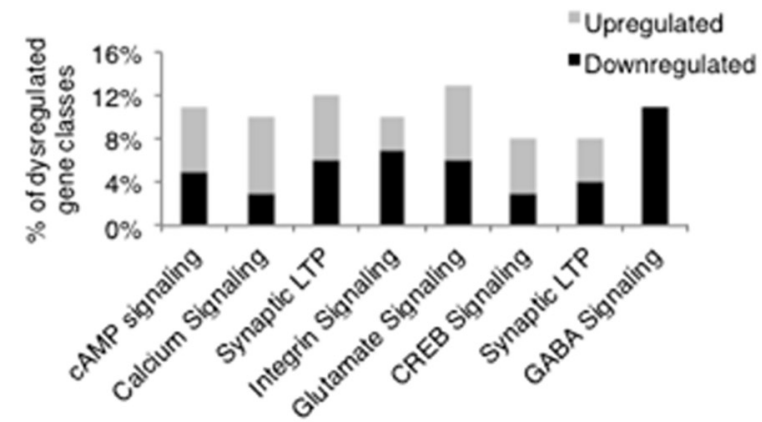

Figure 1. Transcriptome analysis of WT and NFATc4 ${ }^{-1-}$ differentiating NPCs from adult DG. $\boldsymbol{A}$, Unsupervised cluster analysis of differentially regulated genes expressed in WT versus NFATc $4^{-1-}$ NPCS clearly segregates with genotypes. Upregulated genes are represented in red and downregulated genes are in green. $\boldsymbol{B}$, Ingenuity pie chart showing the percentage of neuronal-activity-dependent pathways (green), including GABAergic signaling, over the total number of dysregulated pathways $(p>0.5)$ in NFATc4 ${ }^{-1-}$ versus WT NPCs. C, Bar graphs of neuronal-activity-dependent pathways with relative percentage of dysregulated genes showing that only GABAergic signaling is entirely downregulated in NFATc4 ${ }^{-/-}$versus WT NPCS. 
A

Mus musculus (chromosome 5

GABRA2

GABRA4

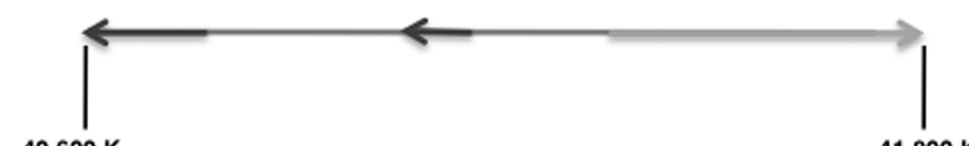

$40,600 \mathrm{~K}$
B

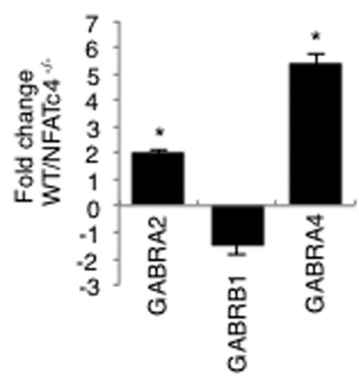

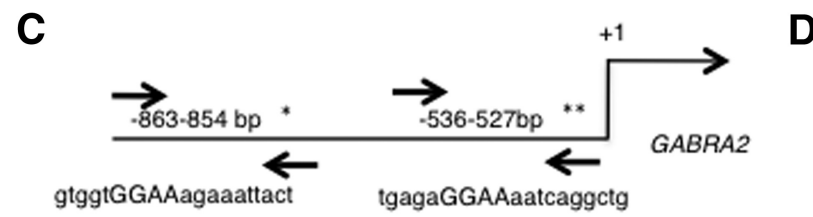
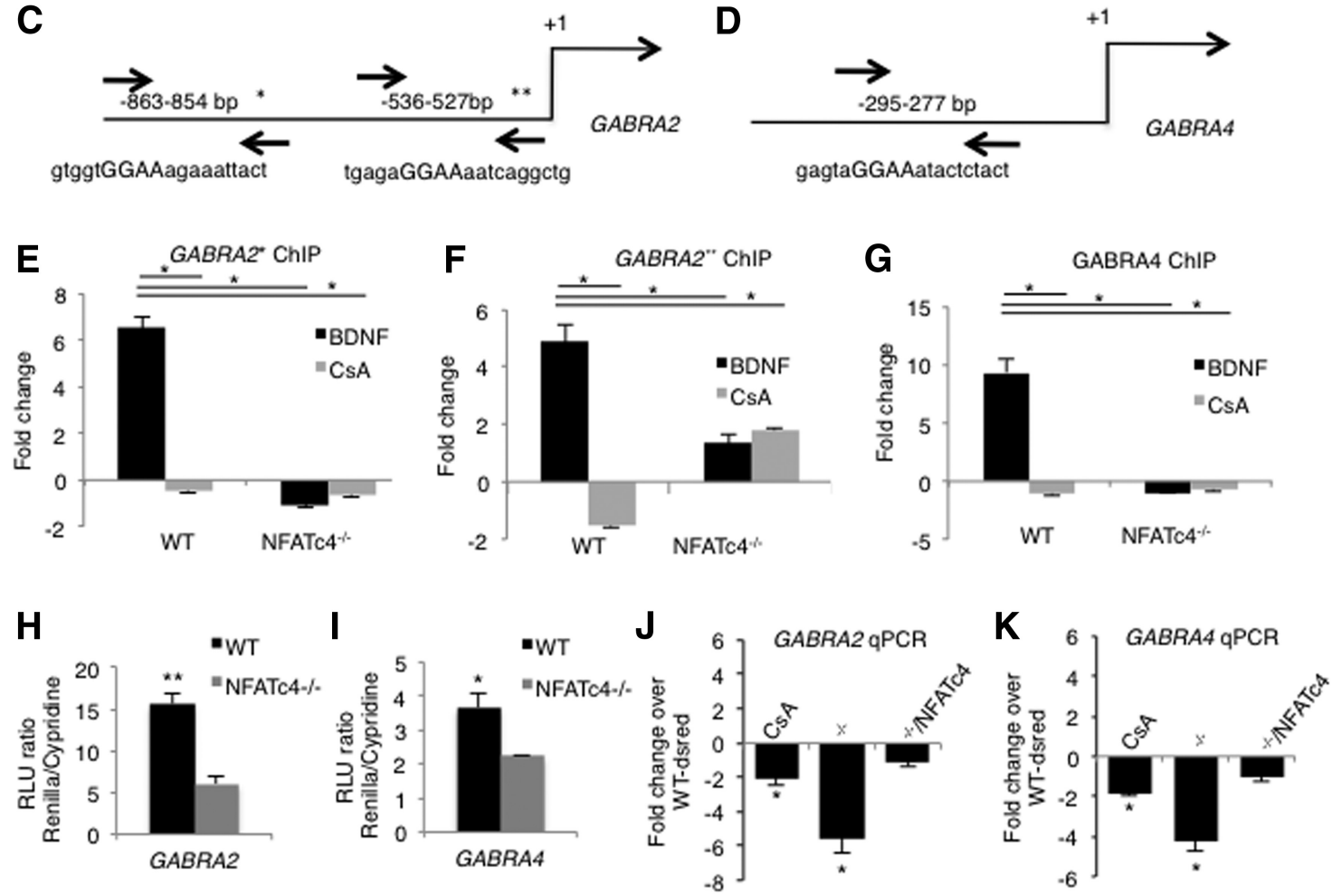

Figure 2. GABRA2 and GABRA4 promoters contain functional NFAT-binding sites. $A$, Schematic of the genomic cluster on chromosome 5 (Mus musculus) containing GABRA2, GABRA4, and GABRAB1 genes. $\boldsymbol{B}$, qRT-PCR analysis showing the mRNA expression level of GABRA2, GABRA4, and GABRAB1 genes in WT and NFATc4 ${ }^{-1-}$ NPCs differentiated for $20 \mathrm{~h}$ in the presence of BDNF (100 $\mathrm{ng} / \mathrm{ml}$ ). Data are normalized to GAPDH expression and are represented as the fold change of WT over NFATC $4^{-1-}$. Data are shown as mean \pm SEM; $n=3$. $C, \boldsymbol{D}$, Diagrams show putative binding sites (Matlnspector) for NFATc4 on the promoter region of the GABRA2 (C) and GABRA4 (D) genes. $\boldsymbol{E}-\boldsymbol{G}$, ChIP assays indicating that NFATc4 occupies two NFAT-responsive elements on the GABRA2 and one on the GABRA4 promoter, showing enrichment of NFATc4 immunoprecipitation compared with lgG control in WT but not in NFATc4 ${ }^{-/-}$NPCs (fold change). CsA blocks NFATc4 occupancy on both GABRA2 and GABRA4 promoters; one-way ANOVA followed by Bonferroni post hoc test: ${ }^{*} p<0.01 ; n=3$. $\boldsymbol{H}, \boldsymbol{I}$, Dual luciferase reporter assay. Luciferase activity was calculated as the ratio of Renilla/Cypridine luciferase signal in WT and NFATc4 ${ }^{-1-}$ NPCs cultured in presence of BDNF $(100 \mathrm{ng} / \mathrm{ml})$ for $6 \mathrm{~h}$. RLU, Relative luminescence unit. Data are shown as mean \pm SEM; $n=3$. ${ }^{*} p<$ 0.05 ; ${ }^{* *} p<0.01$, Student's $t$ test. J, $\boldsymbol{K}$, qRT-PCR analysis for GABRA2 (J) or GABRA4 (K) genes in WT NPCs infected with dsred retrovirus (WT-dsred) and treated with CSA (100 ng/ml), NFATc4 - /cells infected with dsred retrovirus (NFATc4 ${ }^{-1-}$-dsred), or NFATc4-dsred retrovirus (NFATc4 ${ }^{-1-}$-NFATc4-dsred) and treated with vehicle. Data are expressed as the fold change over WT dsred gene expression levels. Data are shown as mean $\pm \mathrm{SEM} ; n=3$; one-way ANOVA followed by Bonferroni post hoc test: ${ }^{*} p<0.05$.

showed that up to $20 \%$ of all the dysregulated pathways are neuronal activity dependent (Fig. $1 B$ ). Interestingly, as opposed to other pathways, all of the differentially regulated genes belonging to the GABAR signaling show downregulation in the absence of NFATc4 expression (Fig. 1C), suggesting NFATc4 as a transcriptional node in the control of GABA signaling. Interestingly, among the members of the GABAergic signaling that were downregulated in NFATc $4^{-/-}$cells, the subunits of the $\mathrm{GABA}_{\mathrm{A}} \mathrm{R} \alpha 2$ (GABRA2), $\alpha 4$ (GABRA4), and betal (GABRAB1) localize in the same genomic cluster on chromosome 5 (Fig. $2 A$ ), suggesting direct transcriptional coregulation of these subunits by NFATc4.

Next, we validated gene expression changes of the GABRA2, $G A B R A 4$, and $G A B R A B 1$ subunits by qRT-PCR. We found that only the GABRA2 and GABRA4 transcripts showed $>2$-fold downregu- lation (fold change \pm SEM: GABRA2: $2.0 \pm$ 0.043; GABRB1: $-1.5 \pm 0.2$; GABRA4: $5.4 \pm 0.17$; Fig. $2 B$ ) in the absence of NFATc4, so these two subunits became the focus of further experiments.

\section{NFATc4 regulates GABAergic signaling in hippocampal progenitor cells via functional binding to GABRA2 and GABRA4 promoters}

To determine whether GABRA subunits are direct transcriptional targets of NFATc4, we analyzed GABRA2 and GABRA4 promoter regions for NFAT consensus binding sites using the MatInspector algorithm of Genomatix software. We found two consensus sites in the promoter region of GABRA2 and one in the promoter region of $G A B R A 4$ localized, respectively, 863,536 , and 295 bp upstream of the transcription start site (Fig. 2C,D). To validate the in silico analysis, we performed a ChIP assay on WT 
A

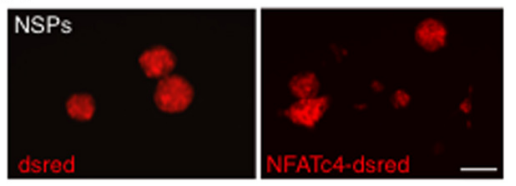

C
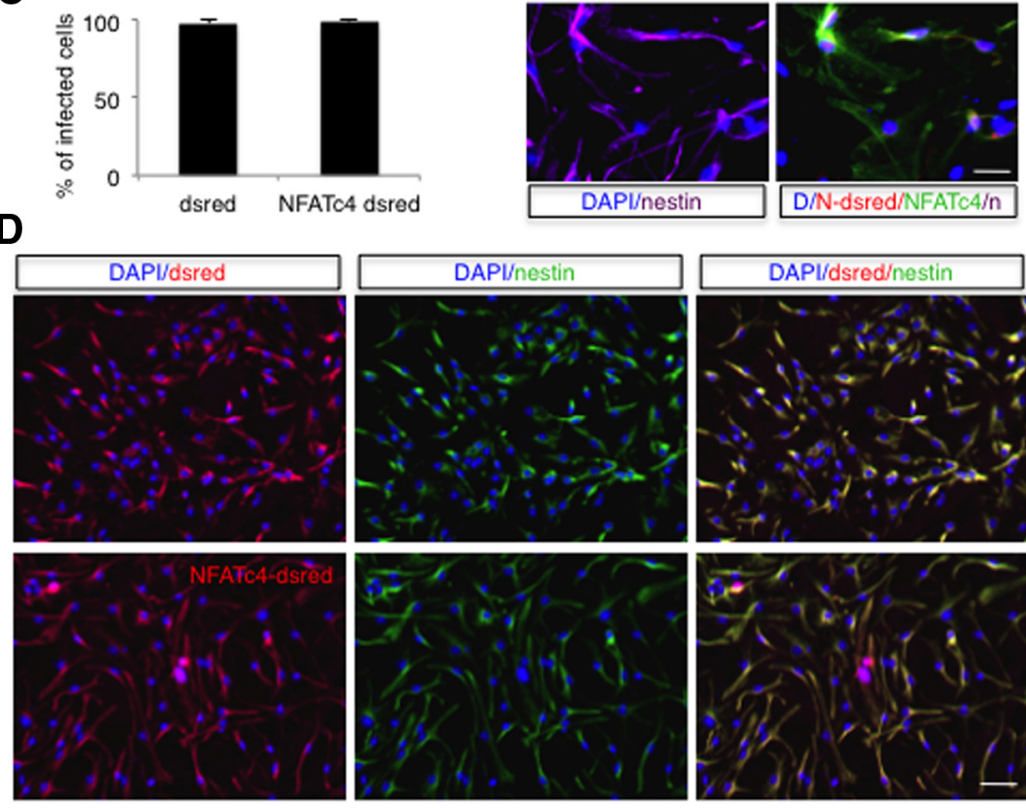

Figure 3. Efficiency and specificity of virus transduction in vitro culture of adult hippocampal NPCs. $\boldsymbol{A}$, Proliferating neurospheres infected with dsred and NFATC4-dsred retrovirus. Scale bar, $200 \mu \mathrm{m}(\boldsymbol{B})$ Immunofluorescence (red, dsred; green, nestin; blue DAPI) in WT NPCs infected with dsred and NFATc4-dsred retrovirus and differentiated for $24 \mathrm{~h}$. Scale bar, $50 \mu \mathrm{m}$. C, Quantification of the number of infected cells with dsred and NFATC4-dsred retrovirus expressed as percentage of the total number of cells (DAPI staining). Data are shown as mean \pm SEM; $n=3 . D$, Immunofluorescence (red, NFATc4-dsred; green, NFATc4; violet, nestin; blue, DAPI) in NFATc4 ${ }^{-1-}$ NPCs infected with NFATC4-dsred retrovirus. Scale bar, $25 \mu \mathrm{m}$.

and NFATc4 ${ }^{-l-}$ differentiated NPCs. As expected, BDNF treatment $(100 \mathrm{ng} / \mathrm{ml})$, which promotes NFATc4 transcriptional activity in NPCs (Quadrato et al., 2012), drove NFATc4 occupancy of the predicted binding sites on the GABRA2 and GABRA4 promoters. Specifically, we found NFATc4 enrichment over IgG control for all binding sites tested (fold change \pm SEM: GABRA2*; WT BDNF, $6.6 \pm 0.5 ; \mathrm{NFATc}^{-1-} \mathrm{BDNF}-1.1 \pm-0.1$; GABRA2 ${ }^{* *}$; WT BDNF, $4.9 \pm 0.6$; NFATc $4^{-1-}$ BDNF $-1.4 \pm-0.2$; GABRA4; WT BDNF, $9.6 \pm 1.1$; NFATc $4^{-1-}$ BDNF $-1.0 \pm-0.04$; Fig. $\left.2 E-G\right)$. Importantly, treatment with CsA, a specific inhibitor of calcineurin/NFAT activity, fully counteracted NFATc4 binding on the GABRA2 and GABRA4 promoters (fold change \pm SEM: GABRA2*; WT CsA, $-0.5 \pm 0.21$; NATc4 ${ }^{-l-} \mathrm{CsA},-0.7 \pm 0.5 ; \mathrm{GABRA}^{* *}$; WT CsA, $-1.6 \pm 0.25$ NFATc4 $^{-l-}$ CsA, $1.8 \pm 0.3$; GABRA4; WT CsA, $-1.2 \pm 0.25$; NFATc $4^{-/-}$CsA, $-0.7 \pm 0.5$; Fig. $\left.2 E-G\right)$. As expected, there was no enrichment in binding over the IgG control in NFATc4 ${ }^{-/-}$NPCs after both BDNF and CsA treatments (Fig. $2 E-G)$. To functionally demonstrate NFATc4 transcriptional activity on GABRA2 and GABRA4 promoters, we cotransfected BDNF-treated WT and NFATc4 ${ }^{-1-}$ NPCs with an artificial luciferase reporter construct driven by either GABRA2 or GABRA4 promoters and a constitutively active reporter control construct driven by the HSV-TK promoter. We observed that BDNF activated both the GABRA2 and GABRA4 promoters in WT hippocampal progenitors and that this was significantly impaired in NFATc4 ${ }^{-1-}$ cells (mean \pm SEM: GABRA2; WT BDNF, $15.5 \pm 1.4$, NFATc $4^{-1-}$ BDNF $6.04 \pm 0.82$, GABRA4; WT BDNF, $3.7 \pm 0.4$,
NFATc4 ${ }^{-1-}$ BDNF $2.23 \pm 0.03$; Fig. $2 H, I)$, suggesting NFATc4 as a direct transcriptional regulator of GABRA2 and GABRA4 gene expression.

Next we investigated whether NFATc4 expression and activity regulates $G A B R A 2$ and GABRA4 mRNA and protein expression in hippocampal NPCs. To this end, we used a retrovirus overexpressing NFATc4-dsred to rescue NFATc4 levels in NFATc $4^{-1-}$ NPCs. As shown in Figure 3, $A-C$, the percentage of cells infected with either the control (dsred) or NFATc4dsred-overexpressing retroviruses was close to $100 \%$. Furthermore, immunostaining confirmed NFATc4 protein expression in infected NFATc4 ${ }^{-1-}$ cells (Fig. 3D). Quantification of GABRA2 and GABRA4 mRNA levels in WT and NFATc4 ${ }^{-/-}$NPCs transduced with a control retrovirus demonstrated that, compared with the WT NPCs, GABRA2 and GABRA4 mRNA levels decreased in the absence of NFATc 4 or after blocking of NFAT activity via CsA treatment (Fig. $2 J, K$ ). Importantly, we found that GABRA2 and GABRA4 expression was fully rescued in NFATc4 ${ }^{-1-}$ cells transduced with the NFATc4-dsred retrovirus compared with WT cells infected with the control virus (fold change \pm SEM: GABRA2; WT CsA dsred, $-2.1 \pm 0.2$ NFATc $^{-l-}$ dsred, $-5.6 \pm 0.47$; NFATc4 $4^{-1-}$ NFATc4-dsred, $-1.2 \pm$ 0.12; GABRA4; WT CsA dsred, $-1.9 \pm$ 0.1 ; NFATc4 $^{-1-}$ dsred, $-4.2 \pm 0.51$; NFATc4 ${ }^{-1-}$ NFATc4-dsred, $-1.05 \pm$ 0.2 ; Fig. $2 J, K)$.

We then analyzed whether NFATc4 expression and activity correlates with increased GABRA2 and GABRA4 protein expression at the single-cell level. Indeed, immunocytochemistry proved that the number of cells expressing high levels of GABRA2 and GABRA4 was significantly lower in differentiating NFATc $4^{-1-}$ compared with WT NPCs (mean \pm SEM: GABRA2; WT, $41.85 \pm 1.9 \%$; NFATc $4^{-1-}, 1.7 \pm 1.13 \%$; $p<0.001$, Student's $t$ test; GABRA4; WT, $65.23 \pm 7.9 \%$; NFATc4 ${ }^{-1-}, 10.1 \pm 4.05 \%$; Fig. $\left.4 A-D\right)$. Consistent with these data, inhibition of calcineurin-dependent NFATc4 transcriptional activity by CsA $(100 \mathrm{ng} / \mathrm{ml})$ treatment in WT NPCs phenocopied NFATc $4^{-1-}$ cells (mean \pm SEM: GABRA2; NFATc $^{-1-}, 1.7 \pm 1.13 \%$; WT CsA $4.9 \pm 2.1 \%$; $p<$ 0.001 , Student's $t$ test; GABRA4; NFATc4 ${ }^{-\prime-}, 10.1 \pm 4.05 \%$; WT CsA, $6.1 \pm 2.3 \%$; Fig. $4 A-D$ ). Furthermore, by single-cell analysis of transfected cells, we found that NFATc4 overexpression in NFATc $4^{-1-}$ cells rescued GABRA2 and GABRA4 protein levels (Fig. $4 E, F$ ). Finally, in support of the hypothesis that NFATc4 transcriptional activity drives GABRA2 and GABRA4 expression, we observed that NFATc4 nuclear localization correlated with increased expression of $\mathrm{GABA}_{\mathrm{A}} \mathrm{R}$ subunits (Fig. 4E,F).

\section{GABAergic excitation increases NFATc4 transcriptional} activity on GABRA 2 and GABRA 4 promoter via calcineurin activation in early neural stem/progenitor cells

Calcium signaling tightly regulates NFATc4 activation and function through calcineurin activity (Shaw et al., 1995). Given that GABAergic depolarization increases intracellular $\mathrm{Ca}^{2+}$ via acti- 
vation of $\mathrm{Ca}^{2+}$ channels and via release of $\mathrm{Ca}^{2+}$ from internal stores (Ge et al., 2007; Young et al., 2010), we hypothesized that $\mathrm{GABRA}_{\mathrm{A}} \mathrm{R}$ stimulation might increase NFATc4 activity in hippocampal progenitors. To determine NFATc4 responsiveness to $\mathrm{GABA}_{\mathrm{A}} \mathrm{R}$ stimulation, we cotransfected WT vehicle-treated or WT CSA-treated NPCs with an artificial luciferase reporter construct driven by either GABRA2 or GABRA4 promoters and a constitutively active reporter control construct driven by HSV-TK promoter. After $24 \mathrm{~h}$ in differentiating conditions, we stimulated NPCs with either a vehicle or the $\mathrm{GABA}_{\mathrm{A}} \mathrm{R}$ agonist muscimol (10 $\mu \mathrm{m})$ for $6 \mathrm{~h}$ and found that luciferase activity increased in response to $\mathrm{GABA}_{\mathrm{A}} \mathrm{R}$ stimulation for GABRA2 and GABRA4 promoters compared with a vehicle (mean \pm SEM: GABRA2; WT vehicle, $1.8 \pm 0.4$; WT muscimol, $5.1 \pm 1.2$; GABRA4; WT vehicle, $2.7 \pm 0.75$; WT muscimol, $5.8 \pm 0.8$; Fig. $5 A, B$ ). In addition, CsA treatment blocked the $\mathrm{GABA}_{\mathrm{A}} \mathrm{R}$-mediated enhancement in luciferase activity on both promoters (Fig. $5 A, B)$, suggesting that GABAergic transmission regulates NFATc4 transcriptional

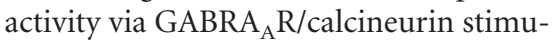
lation (mean \pm SEM: GABRA2; WT CsA vehicle, $2.6 \pm 0.5$; WT CsA muscimol, $3.1 \pm 0.7$; GABRA4; WT CsA vehicle, $3.0 \pm 0.7$; WT CsA muscimol, $3.6 \pm 1.0$ ). Consistent with these data, immunocytochemistry showed that, compared with the vehicle, a significantly higher number of differentiating NPCs exhibited increased NFATc4 nuclear translocation upon muscimol administration and this was fully blocked by CsA treatment (mean \pm SEM: WT vehicle, $14.6 \pm 2.3 \%$; WT muscimol, $34.0 \pm 4.6 \%$; WT CsA vehicle, $4.3 \pm 2.1 \%$; WT CsA muscimol, $6.6 \pm 1.5 \%$; Fig. $5 C, D$ ). Importantly, the majority of the cells that exhibit increased GABRA2 and GABRA4 expression and NFATc4 nuclear translocation are positive for the neural stem cells markers Sox 2 and Hes5 (Ferri et al., 2004; Lugert et al., 2010) and negative for Neurod1, a marker of neuroblasts (Gao et al., 2009), suggesting that the $\mathrm{GABA}_{\mathrm{A}} \mathrm{R} / \mathrm{NFAT} \mathrm{C} 4$ axis is active in early stem/progenitor cells (Fig. $5 E, F$ ).

Altogether, these data suggest a positive excitatory feedback loop between GABAergic signaling and NFATc4 activity in which stimulation of $\mathrm{GABA}_{\mathrm{A}} \mathrm{R}$ increases calcineurin/NFATc4 activity that in turn regulates GABRA2 and GABRA4 expression directly in early adult hippocampal stem/progenitor cells.

\section{$\mathrm{GABA}_{\mathrm{A}} \mathrm{R}$ stimulation promotes adult hippocampal neurogenesis via NFATc4 activity}

GABAergic excitation controls neuronal differentiation, integration, and maturation of neural progenitors (Tozuka et al., 2005; Ge et al., 2006). To investigate whether NFATc4 signaling is re-
B

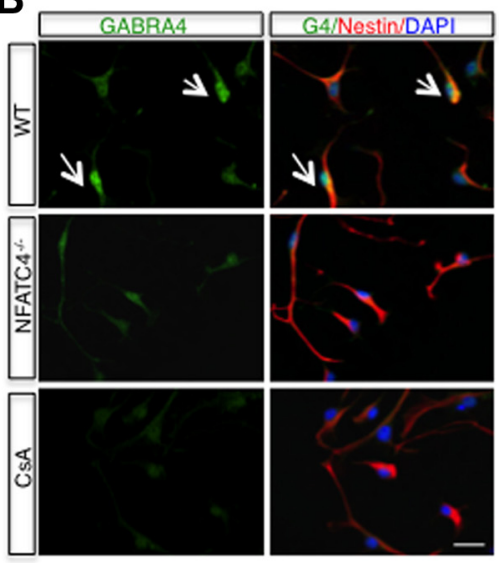

D

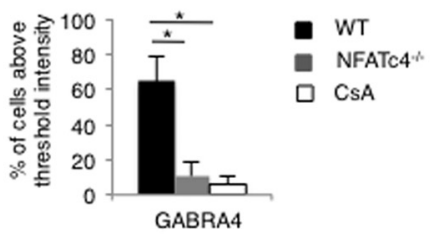

$\mathbf{F}$

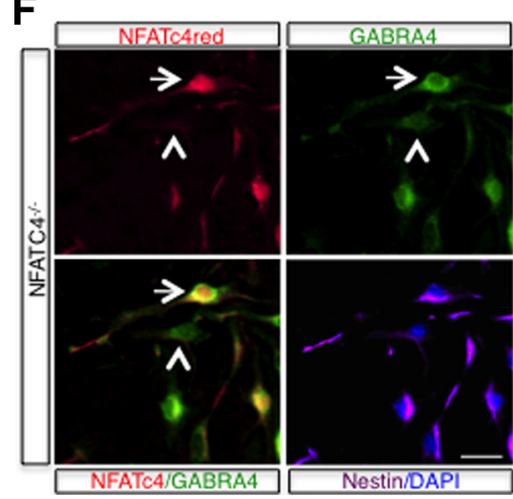

Figure 4. NFATC4 regulates GABRA2 and GABRA4 gene and protein expression via calcineurin. $A, B, I$ Immunofluorescence (red, J. Scale bar, $25 \mu \mathrm{m} C, D$, Quantification of the number of cells with a staining intensity for anti-GABRA2 or anti-GABRA4 dsred retrovirus. Arrows indicate cells with strong nuclear expression of NFATc4-dsred. Arrowheads indicate cells with low expression of dsred-NFATc4. Scale bar, $25 \mu \mathrm{m}$.

quired for GABAergic control of hippocampal neurogenesis, we tested whether GABAergic excitation would affect neuronal differentiation via NFATc4. To this end, we infected WT and NFATc $4^{-1-}$ NPCs with either the control or NFATc4-dsred retrovirus and then treated the cells with a vehicle or with muscimol $(10 \mu \mathrm{M})$, a specific $\mathrm{GABA}_{\mathrm{A}} \mathrm{R}$ agonist, to enhance GABAergic transmission. After $1 \mathrm{~d}$ of differentiation, cells were fixed and double immunolabeled for nestin and for the neuronal marker MAP2 to detect the percentage of cells committed toward neuronal lineage. After $1 \mathrm{~d}$ in differentiating conditions, we observed 4 different populations derived from WT NPCs transduced with the control virus (Fig. 6A,B). Indeed, at this stage, most of the cells $(\sim 70 \%)$ are still undifferentiated and positive only for nestin (mean \pm SEM: WT dsred vehicle-treated, $71 \pm 1.9 \%$; WT dsred CsA and vehicle-treated, $68.5 \pm 0.2 \%$ NFATc $^{-1-}$ dsred vehicle-treated, $68.0 \pm 1.4 \%$ ); $\sim 20 \%$ are already committed to 
A

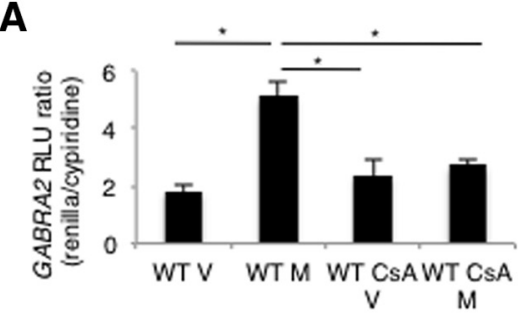

B

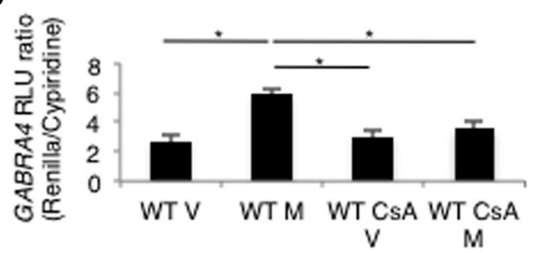

D

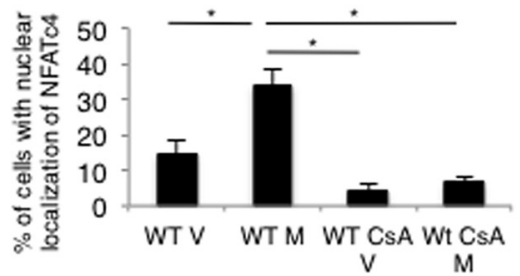

C
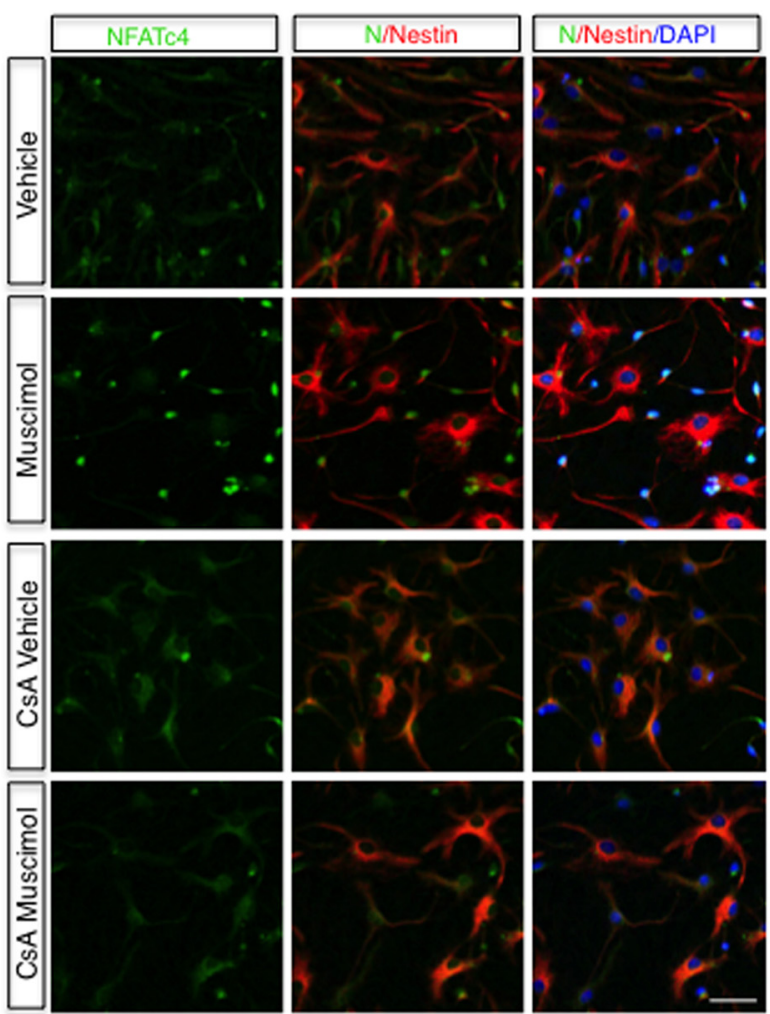

$\mathbf{F}$
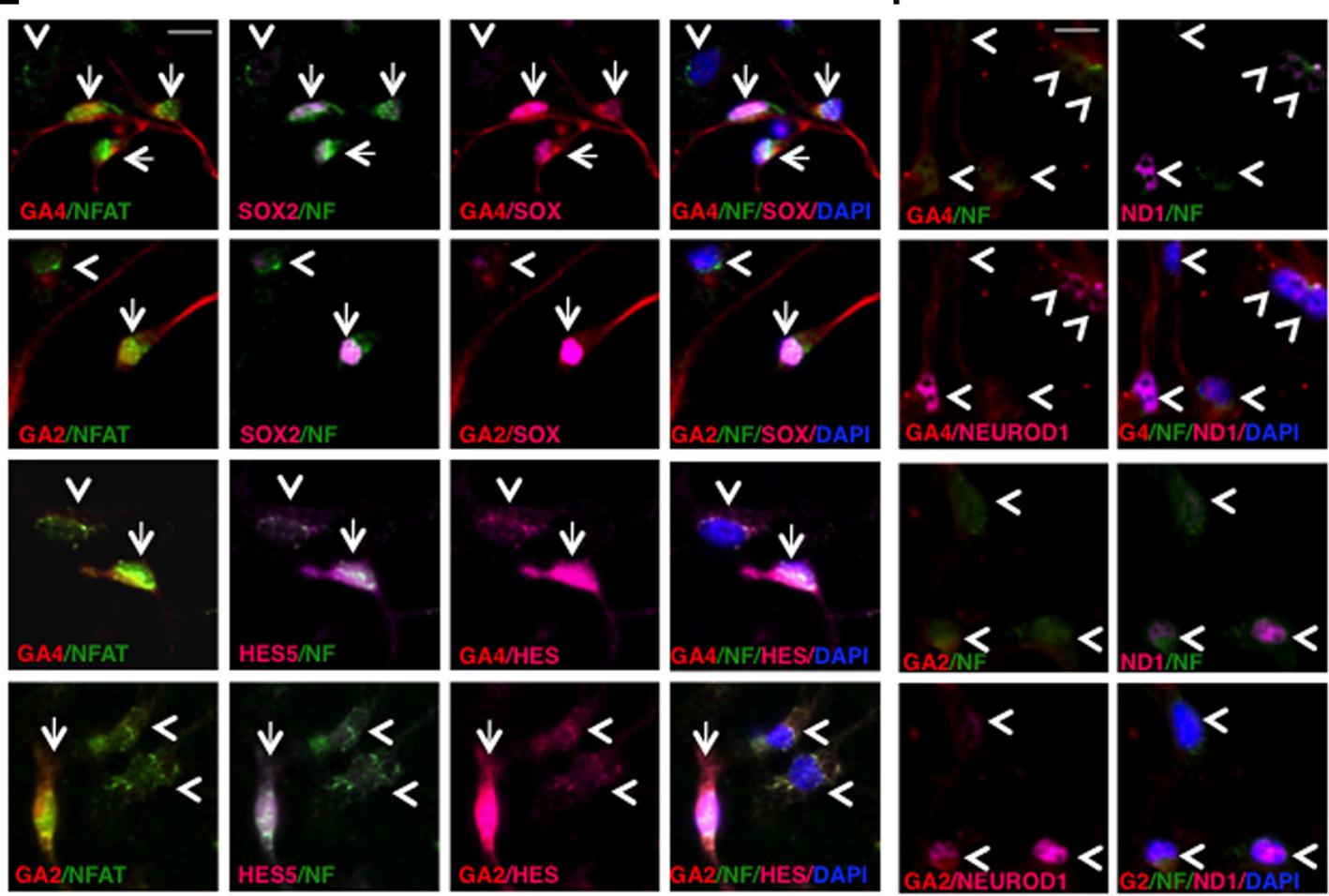

Figure 5. GABAergic excitation increases NFATC4 transcriptional activity on GABRA2 and GABRA4 promoter via calcineurin activation in early neural stem/progenitor cells. $A, B$, Dual luciferase reporter assay. Luciferase activity was calculated as the ratio of Renilla/Cypridine luciferase signal in WT and WT-CsA-treated hippocampal NPCs cultured in presence of either vehicle or muscimol (10 $\mu \mathrm{m}$ ) for $6 \mathrm{~h}$. RLU, Relative luminescence unit. Data are shown as mean $\pm \mathrm{SEM} ; n=3$; one-way ANOVA followed by Bonferroni post hoc test: ${ }^{*} p<0.01$; ${ }^{* *} p<0.001$. C, Immunofluorescence (red, nestin; green, NFATc4; blue, DAPI) in WT vehicle, WT CsA (100 ng/ml), WT muscimol (10 $\mu \mathrm{m})$, and WT CsA + muscimol-treated NPCs differentiated for $24 \mathrm{~h}$ shows enhancement of NFATc4 nuclear localization after muscimol, which is abolished by CsA. Scale bar, $25 \mu \mathrm{m}$. D, Quantification of the number of cells with nuclear localization of NFATc4 $\left(\boldsymbol{C} ;\right.$ DAPI $\left.^{+}\right)$. Data are expressed as a percentage of the total number of viable cells. Approximately 100 cells were counted for each of three different coverslips. Data are shown as mean $\pm \mathrm{SEM} ; n=3$; one-way ANOVA followed by Bonferroni post hoc test: ${ }^{*} p<0.05$; ${ }^{* *} p<0.001 . E, F$, Immunofluorescence [red, GABRA2 (GA2) or GABRA4 (GA4); green, NFATc4 (NF); pink, Sox2 (sox), HES5 (Hes), or NeuroD1 (ND1); blue, DAPI] in WT muscimol $(10 \mu \mathrm{m})$-treated NPCs differentiated for $24 \mathrm{~h}$. Shown is an increase in GABRA2 and GABRA4 expression and enhancement of NFATc4 nuclear localization in Sox2 ${ }^{+}$and HES5 ${ }^{+}$cells but not in NeuroD1 ${ }^{+}$cells in muscimol-treated NPCs. Arrows indicate cells with strong nuclear expression of NFATc4. Arrowheads indicate cells with low nuclear expression of NFATc4. Scale bar, $20 \mu \mathrm{m}$. 
A
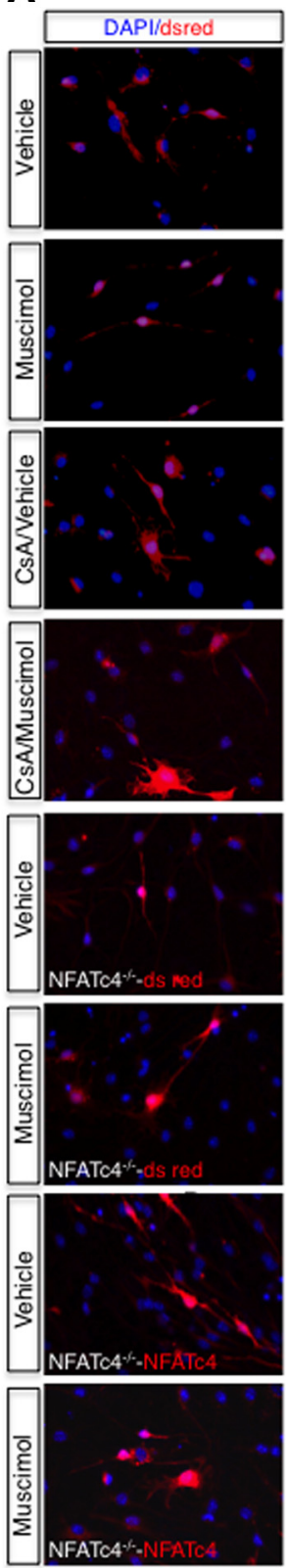
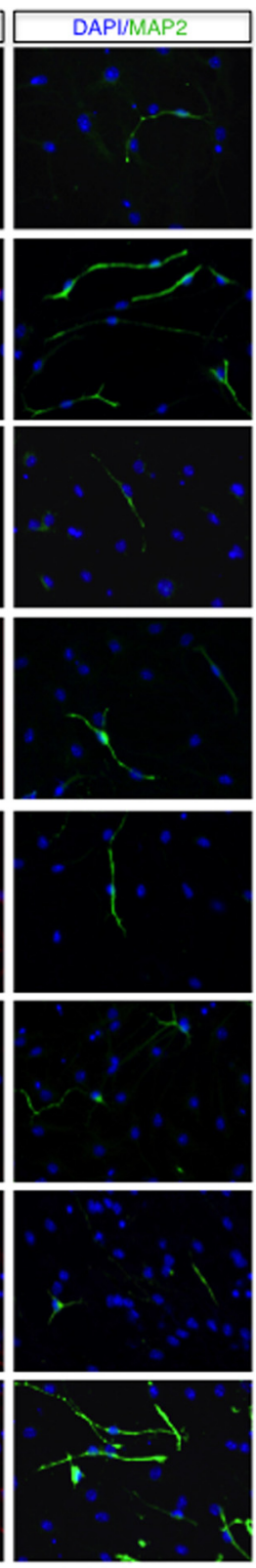
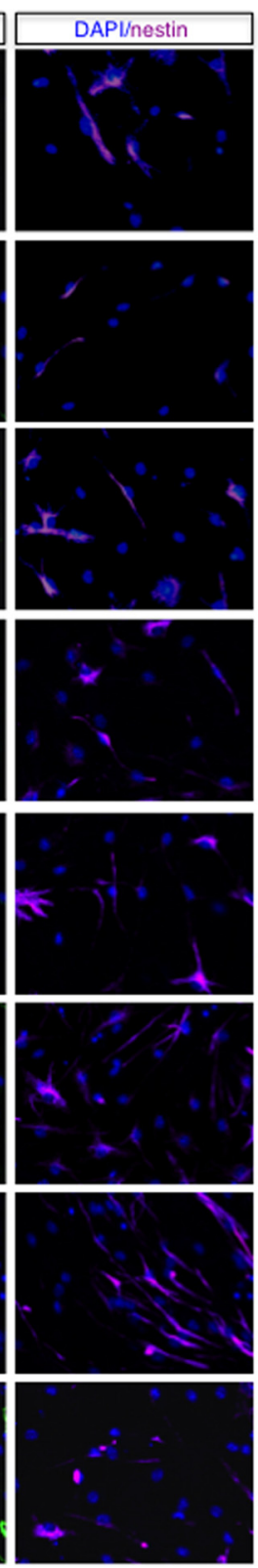

B
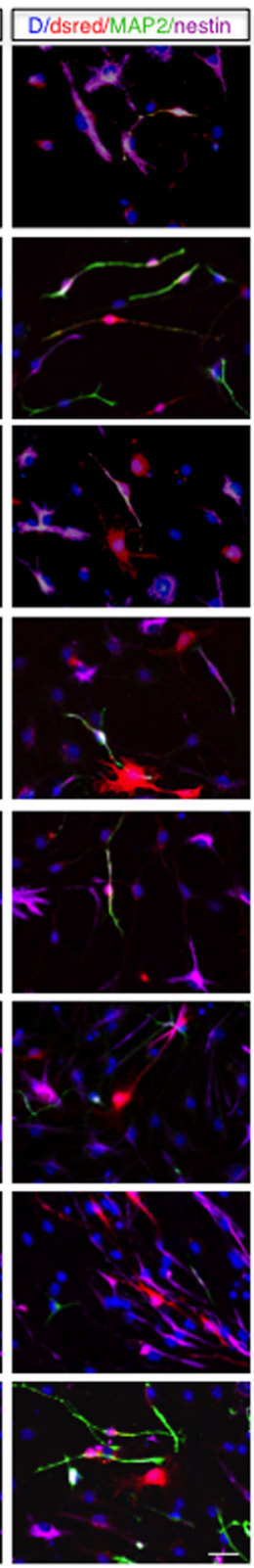
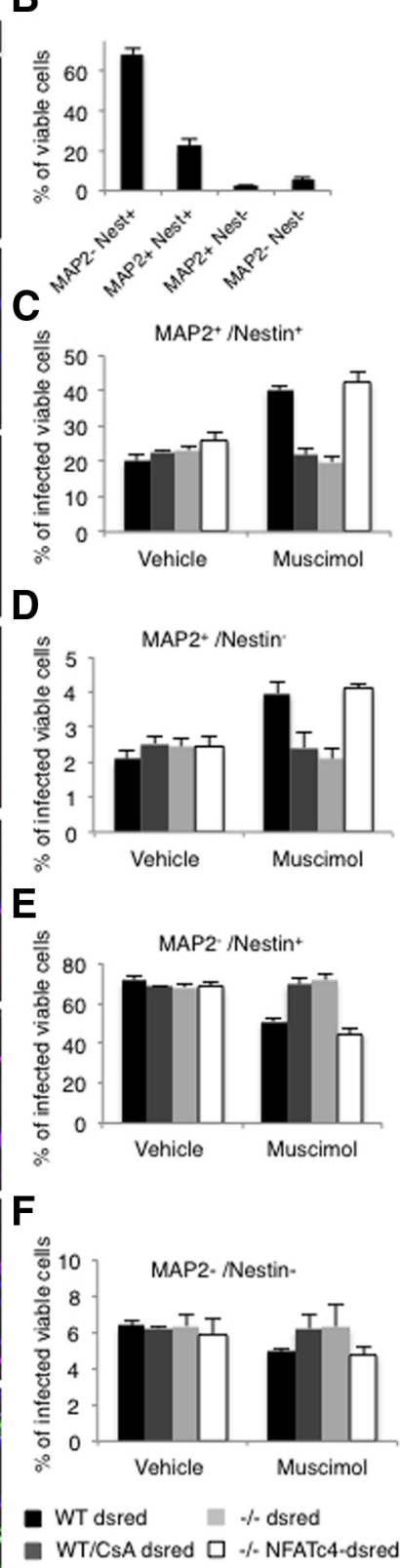

Figure 6. Enhancement of $\mathrm{GABA}_{A} \mathrm{R}$ signaling promotes neuronal differentiation of cultured NPCs via NFATc4 activity. A, Immunofluorescence staining (red, dsred or NFATc4-dsred; green, MAP2; violet, nestin and blue DAPI) of WT, WT CsA-treated (100 ng/ml) and NFATC4 ${ }^{-1-}(-/-)$, and NFATC4 ${ }^{-1-}$ CsA-treated NPCs, differentiated for $24 \mathrm{~h}$ in presence of vehicle or muscimol (10 $\left.\mu \mathrm{m}\right)$. Scale bar, $25 \mu \mathrm{m} . B$, Quantification of the number ofWTNPCs, cultured for $20 \mathrm{~h}$ in differentiating conditions and belonging to four different populations expressing, respectively: nestin, MAP2, nestin + MAP2, or none of the two markers. Data are expressed as percentage of the total number of viable cells (DAPI staining). Approximately 100 cells were counted for each of three different coverslips. Data are shown as mean \pm SEM; $n=3 . \mathbf{C}-\boldsymbol{F}$, Quantification of the number of WT-dsred, WT-dsred CsA-treated, NFATC4 ${ }^{-1-}$-dsred, and NFATC4 ${ }^{-1-}$-NFATC4-dsred NPCS cultured for $20 \mathrm{~h}$ in differentiating conditions and belonging to four different populations expressing, respectively: nestin, MAP2, nestin + MAP2, or none of the two markers after treatment with either vehicle or muscimol $(10 \mu \mathrm{m})$. Data are expressed as percentage of the total number of viable cells (DAPI staining). Approximately 100 cells were counted for each of three different coverslips. Data are shown as mean $\pm \mathrm{SEM} ; n=3$; one-way ANOVA followed by Bonferroni post hoc test (see Table 1 for statistics).

neuronal lineage (positive for MAP2) but still retain nestin expression (mean \pm SEM: WT dsred vehicle-treated, $20.2 \pm 1.7 \%$; WT dsred CsA and vehicle-treated, $22.7 \pm 0.46 \%$ NFATc $^{-1-}$ vehicle-treated, $23.2 \pm 1.1 \%$ ); only $\sim 2 \%$ of the cells are already fully differentiated (nestin ${ }^{-}$and $\mathrm{MAP}^{+}{ }^{+}$; mean \pm SEM: WT dsred vehicle-treated, $2.1 \pm 0.23 \%$; WT dsred CsA and vehicletreated, $2.53 \pm 0.21 \%$; NFATc $4^{-1-}$ vehicle-treated, $2.44 \pm$ $0.23 \%$ ); and $\sim 6 \%$ of the total number of cells were negative for both markers (mean \pm SEM: WT dsred vehicle-treated, $6.4 \pm$ $0.1 \%$; WT dsred CsA and vehicle-treated, $6.21 \pm 0.1 \%$;
NFATc $4^{-l-}$ vehicle-treated, $6.35 \pm 0.6 \%$; see Fig. $6 B-F$, Table 1 for statistics). Compared with the vehicle-treated group, a higher percentage of WT cells treated with muscimol differentiate toward neuronal lineage, showing a significant increase in both $\mathrm{MAP}^{+} /$nestin ${ }^{-}(\sim 4 \%$; mean \pm SEM: WT dsred muscimoltreated, $4.0 \pm 0.3 \%)$ and $\mathrm{MAP}^{+} /$nestin $^{+}(\sim 40 \%$; mean \pm SEM: WT dsred muscimol-treated, $40.3 \pm 1 \%)$ populations and a decrease in the number of undifferentiated cells (see Fig. $6 B-F$, Table 1 for statistics). Conversely, NFATc $4^{-1-}$ cells treated with muscimol do not show significant change in differentiation rate 
Table 1. Treatment comparisons

\begin{tabular}{|c|c|c|c|c|}
\hline & $\mathrm{MAP2}^{+} /$Nestin $^{+}$ & $\mathrm{MAP2}^{+} /$Nestin $^{-}$ & MAP2 $^{-}$/Nestin $^{+}$ & MAP2 $^{-} /$Nestin $^{-}$ \\
\hline WT dsred Veh vs WT dsred CsA Veh & NS & NS & NS & NS \\
\hline WT dsred Veh vs NFATc4 ${ }^{-1-}$ dsred Veh & NS & NS & NS & NS \\
\hline WT dsred Veh vs NFATc4 ${ }^{-1-}$ NFATc4 dsred Veh & NS & NS & NS & NS \\
\hline WT dsred Veh vs WT dsred M & $p=0.0002$ & $p=0.011$ & $p=0.0025$ & NS \\
\hline WT dsred Veh vs WT dsred CsA M & NS & NS & NS & NS \\
\hline WT dsred Veh vs NFATc $4^{-I-}$ dsred M & NS & NS & NS & NS \\
\hline WT dsred Veh vs NFATc4 ${ }^{-l-}$ NFATc4 dsred M & $p<0.0001$ & $p=0.0168$ & $p=0.0014$ & NS \\
\hline WT dsred CsA Veh vs NFATc4 ${ }^{-1-}$ dsred Veh & NS & NS & NS & NS \\
\hline WT dsred CsA Veh vs NFATc4 ${ }^{-1-}$ NFATc4 dsred Veh & NS & NS & NS & NS \\
\hline WT dsred CsA Veh vs WT dsred M & $p=0.0011$ & NS & $p=0.0104$ & NS \\
\hline WT dsred CsA Veh vs WT dsred CsA M & NS & NS & NS & NS \\
\hline WT dsred CsA Veh vs NFATc4 ${ }^{-1-}$ dsred M & NS & NS & NS & NS \\
\hline WT dsred CsA Veh vs NFATc4 ${ }^{-1-}$ NFATc4 dsred M & $p=0.0004$ & NS & $p=0.0056$ & NS \\
\hline NFATc4 ${ }^{-1-}$ dsred Veh vs NFATc4 ${ }^{-1-}$ NFATc4 dsred Veh & NS & NS & NS & NS \\
\hline NFATc4 ${ }^{-I-}$ dsred Veh vs WT dsred M & $p=0.0014$ & NS & $p=0.0138$ & NS \\
\hline NFATc $4^{-1-}$ dsred Veh vs WT dsred CsA M & NS & NS & NS & NS \\
\hline NFATc4 ${ }^{-1-}$ dsred Veh vs NFATc4 ${ }^{-1-}$ dsred M & NS & NS & NS & NS \\
\hline NFATc4 ${ }^{-1-}$ dsred Veh vs NFATc4 ${ }^{-1-}$ NFATC4 ${ }^{-1-}$ dsred M & $p=0.0006$ & NS & $p=0.0074$ & NS \\
\hline NFATc4 ${ }^{-1-}$ NFATc4 dsred Veh vs WT dsred M & $p=0.0171$ & NS & NS & NS \\
\hline NFATc4 ${ }^{-I-}$ NFATc4 dsred Veh vs WT dsred CsA M & NS & NS & NS & NS \\
\hline NFATc4 ${ }^{-I-}$ NFATc4 dsred Veh vs NFATc4 ${ }^{-1-}$ dsred M & NS & NS & NS & NS \\
\hline NFATc $4^{-I-}$ NFATc4 dsred Veh vs NFATc4 ${ }^{-1-}$ rescue M & $p=0.0064$ & NS & $p=0.0428$ & NS \\
\hline WT dsred M vs WT dsred CsA M & $p=0.0006$ & NS & $p=0.006$ & NS \\
\hline WT dsred M vs NFATc $4^{-1-}$ dsred M & $p=0.0002$ & $p=0.0111$ & $p=0.002$ & NS \\
\hline WT dsred M vs NFATc4 ${ }^{-1-}$ NFATc4 dsred M & NS & NS & NS & NS \\
\hline WT dsred CsA M vs NFATc4 ${ }^{-1-}$ dsred M & NS & NS & NS & NS \\
\hline WT dsred CsA M vs NFATc4 ${ }^{-I-}$ NFATc4 dsred M & $p=0.0002$ & NS & $p=0.0033$ & NS \\
\hline NFATc4 ${ }^{-1-}$ dsred M vs NFATc4 ${ }^{-1-}$ NFATc4 dsred M & $p<0.0001$ & $p=0.0169$ & $p=0.0011$ & NS \\
\hline
\end{tabular}

Statistical analyses for Figure $6 C-F$. Comparisons between cells treated either with vehicle or muscimol and transduced with ds-red or NFATC $4 \mathrm{ds}$-red viruses have been calculated between four different cell populations $\left(\right.$ MAP2 ${ }^{+} /$Nestin ${ }^{+}$ $\mathrm{MAP2}^{+}{ }^{\text {NNestin }}{ }^{-}$, MAP2 $^{-}$/Nestin $^{+}$, and MAP2 ${ }^{-} /$Nestin $^{-}$).

compared with vehicle, indicating impaired responsiveness toward GABA signaling induced via $\mathrm{GABA}_{\mathrm{A}} \mathrm{R}$ agonist administration (see Fig. $6 B-F$, Table 1 for statistics). Importantly, muscimol-treated NFATc $4^{-1-}$ cells transduced with NFATc4-dsred retrovirus show a functional rescue, displaying no differences in neuronal differentiation rate compared with WT cells treated with muscimol $\left(\mathrm{MAP}^{+}{ }^{+}\right.$ nestin ${ }^{+}$: mean \pm SEM: NFATc $4^{-1-}$ NFATc4-dsred vehicle-treated, $25.89 \pm 2.6 ;$ NFATc $^{-l-}$ NFATc4-dsred muscimol-treated, $42.4 \pm$ $2.9 \% ; \mathrm{MAP}^{+} /$nestin $^{-}: \mathrm{NFATc}^{-1-} \mathrm{NFATc}^{- \text {dsred vehicle- }}$ treated, $2.42 \pm 0.31 ;$ NFATc $^{-l-}$ NFATc4-dsred muscimol-treated, $4.11 \pm 0.14 \%$; see Fig. $6 C, D$, Table 1 for statistics). Consistent with this evidence, CsA-treated WT NPCs show no response to muscimol administration, phenocopying the NFATc $4^{-1-}$ cells (see Fig. $6 C, D$, Table 1 for statistics). Furthermore, we observed no difference in the survival of NPCs after muscimol administration, as confirmed by quantification of the number of caspase3-positive cells and of the pyknotic nuclei in vehicle versus muscimol-treated NPCs (data not shown).

Importantly, muscimol administration promotes the nuclear localization of NFATc4 in a subpopulation of nestin ${ }^{+}$neural progenitor cells and not in $\mathrm{DCX}^{+}$neuroblasts, confirming that NFATc4 is nuclear and therefore likely active at early stage of adult hippocampal progenitor cells development (Fig. 7).

To determine whether NFATc4 activity is required for $\mathrm{GABA}_{\mathrm{A}} \mathrm{R}$ dependent neuronal differentiation in the adult brain, we injected stereotaxically the control retrovirus expressing dsred into the DG of a group of adult WT and NFATc4 ${ }^{-1-}$ mice or the NFATc4-dsred expressing retrovirus in the DG of NFATc $4^{-/-}$mice to selectively rescue NFATc4 expression in hippocampal progenitor cells. The three groups of mice were then injected daily for $24 \mathrm{~d}$ with either the
$\mathrm{GABA}_{\mathrm{A}} \mathrm{R}$ agonist muscimol $(4 \mathrm{mg} / \mathrm{kg}$ ) or the vehicle (Fig. $8 \mathrm{~A}$ ). We then assessed the effect of GABAergic excitation on hippocampal progenitor cells differentiation by counting the percentage of retrovirus-infected cells positive for the neuronal marker $\mathrm{CB}$ in the three groups of mice. Indeed, the treatment with the $\mathrm{GABA}_{\mathrm{A}} \mathrm{R}$ agonist substantially increased the percentage of neuronal differentiation $\left(\mathrm{CB}^{+} / \mathrm{dsred}^{+}\right.$cells) in WT and in NFATc $4^{-1-}$ mice in which NFATc4 expression was rescued by retrovirus, but not in the absence of NFATc4 (mean \pm SEM: WT dsred vehicle 50.8 $\pm 1.9 \%$; WT dsred muscimol, $78.8 \pm 2.7 \%$; NFATc4 ${ }^{-1-}$ NFATc4-dsred vehicle, $49.16 \pm 5.6 \%$; NFATc4 ${ }^{-1-}$ NFATc4-dsred muscimol, $72.9 \pm 3.76$; Fig. $8 B, C)$. Consistent with these data, we found that, $24 \mathrm{~d}$ after BrdU injections, the total number of $\mathrm{BrdU}^{+} / \mathrm{CB}^{+}$cells increases in muscimol-treated mice compared with vehicle (mean \pm SEM: WT vehicle $1102.338 \pm 91.44$; WT muscimol $1680.42 \pm 128.80)$, whereas the total number of $\mathrm{BrdU}^{+}$cells differentiated toward the glial phenotype $\left(\mathrm{BrdU}^{+} / \mathrm{GFAP}^{+}\right)$decreases after muscimol (mean \pm SEM: WT vehicle $370.57 \pm 106.7$; WT muscimol $135.20 \pm$ 69.55; Fig. $8 E, F)$. Importantly, in NFATc $4^{-1-}$ mice, we observed no effect on the commitment of NPCs after muscimol administration. Moreover, despite the confirmation of a basal difference in NPC survival between WT and NFATc $4^{-1-}$ mice (as we have shown previously: Quadrato et al., 2012), we did not observe a difference in the total number of $\mathrm{BrdU}^{+}$cells in muscimol-treated compared with vehicle-treated WT mice. This confirms that activation of the $\mathrm{GABA}_{\mathrm{A}} \mathrm{R} / \mathrm{NFATc} 4$ axis selectively affects the commitment and not the survival of NPCs (Fig. 8D, G).

Altogether, these data further suggest NFATc4 as a novel and essential regulator of GABAergic excitation in hippocampal adult-born neurons. 

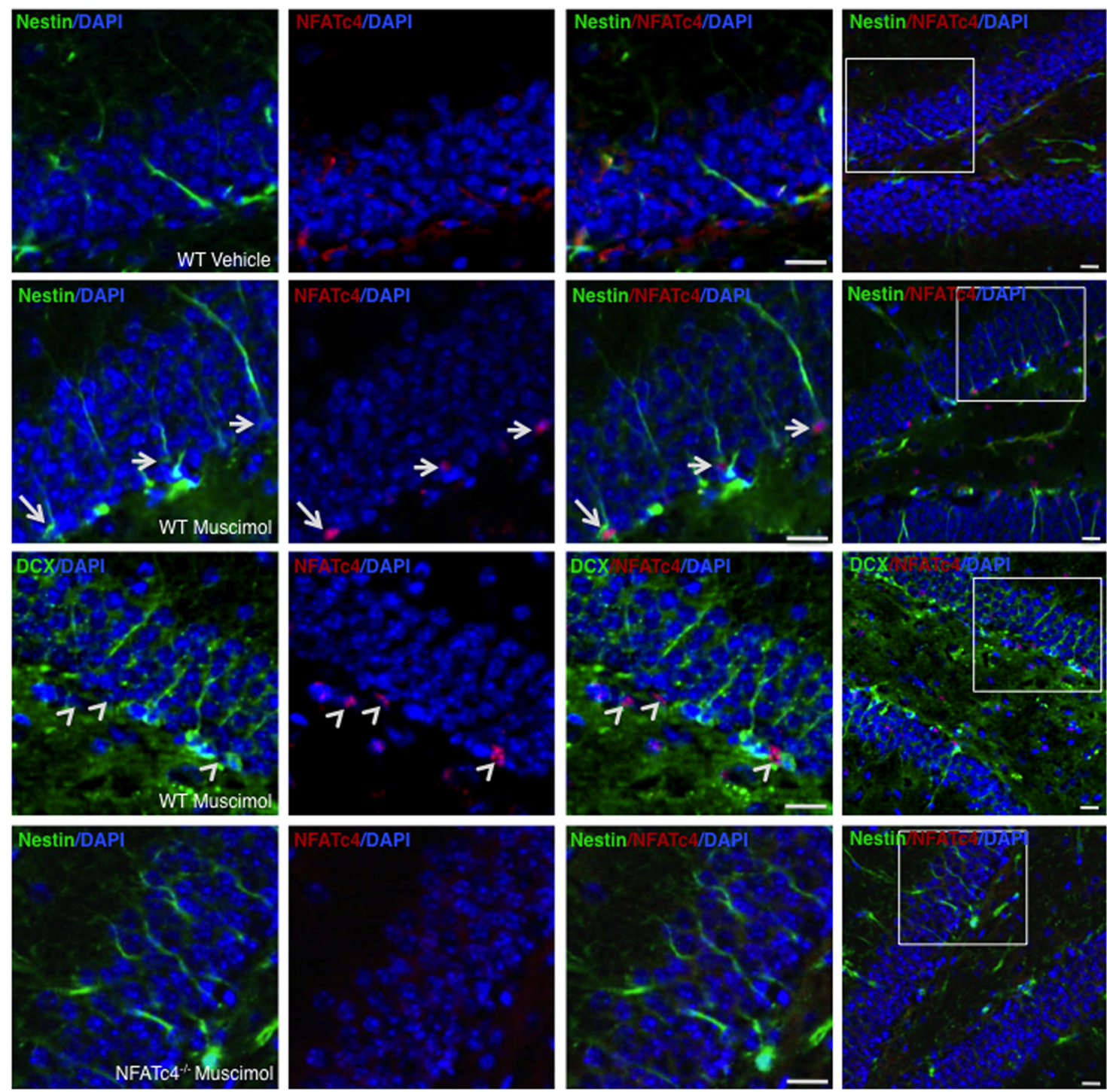

Figure 7. Enhancement of GABAergic signaling promotes NFATc4 activation in early neural stem/progenitor cells. Immunofluorescence staining (red, NFATc4; green, nestin or DCX; blue, DAPI) of cells in the DG of adult mice after treatment with either muscimol or vehicle for $24 \mathrm{~d}$. Arrows indicate nestin ${ }^{+}$cells with NFATc4 nuclear localization. Arrowheads indicate cells with NFATc4 nuclear localization that are not $\mathrm{DCX}{ }^{+}$. Scale bar, $10 \mu \mathrm{m}$.

$\mathrm{GABA}_{\mathrm{A}} \mathrm{R}$-mediated increase in adult hippocampal neurogenesis modulates anxiety response through NFATc4

Administration of $\mathrm{GABA}_{\mathrm{A}} \mathrm{R}$ agonists, including muscimol, decreases the anxiety level in rodents (Zarrindast et al., 2001; Lippa et al., 2005). It has been also shown that increase in adult hippocampal neurogenesis after exposure to enriched environment or drug administration exerts anxiolytic effect in rodents (Santarelli et al., 2003; Schloesser et al., 2010). To elucidate whether chronic GABAergic excitation is able to decrease innate anxiety in mice via NFATc4 activation, we assessed anxiety-like behavior in WT and NFATc $4^{-1-}$ mice after chronic administration of muscimol. Importantly, we have reported previously that NFATc $4^{-1-}$ mice show no differences in basal anxiety level or locomotor performance and that their behavioral impairment is restricted only to the formation of spatial long-term memory (Quadrato et al., 2012). Therefore, NFATc4 ${ }^{-/-}$mice are suitable for studying the modulation of anxiety level after chronic $\mathrm{GABA}_{\mathrm{A}} \mathrm{R}$ stimulation. As a behavioral read out of anxiety levels, we used the EPM, a classical rodent model of anxiety used for testing anxiogenic and anxiolitic compounds (Hogg, 1996). WT and NFATc $4^{-l-}$ mice were injected daily for $24 \mathrm{~d}$ with either muscimol ( $4 \mathrm{mg} / \mathrm{kg}$ ) or vehicle and then $24 \mathrm{~h}$ after the last injection tested in the EPM (Fig. 9A). Consistent with previous data (Quadrato et al., 2012), we found no difference in time spent in open arms between vehicle-injected WT and NFATc4 ${ }^{-l-}$ mice (mean \pm SEM: WT vehicle, $4.12 \pm 1.95 \%$; NFATc $4^{-\prime-}$ vehicle, $18.06 \pm 3.97 \%$; Fig. $9 A-C)$, but, as predicted, we observed a significant increase in the time that WT mice spent in open arms in response to muscimol administration (mean \pm SEM: WT vehicle, $4.12 \pm$ 1.95\%; WT muscimol, $57.02 \pm 10.06 \%$; Fig. 9A-C). Similarly, we found that, consistent with a reduction in anxiety levels, muscimol-treated mice showed a tendency to spend more time in the crossing area and to travel more compared with vehicle-treated mice (Fig. 9E, F). Importantly, this effect was not observed in NFATc4 ${ }^{-1-}$ mice (mean \pm SEM: NFATc4 ${ }^{-1-}$ vehicle, $18.06 \pm 3.97 \%$ NFATc $^{-1-}$ muscimol, $28.28 \pm 3.23 \%$; Fig. $9 A-C)$, confirming that $\mathrm{GABA}_{\mathrm{A}} \mathrm{R}$ stimulation decreases innate anxiety in mice via NFATc4 activation.

To investigate the contribution of adult hippocampal neurogenesis in the NFATc4-mediated modulation of anxiety levels, we 
A

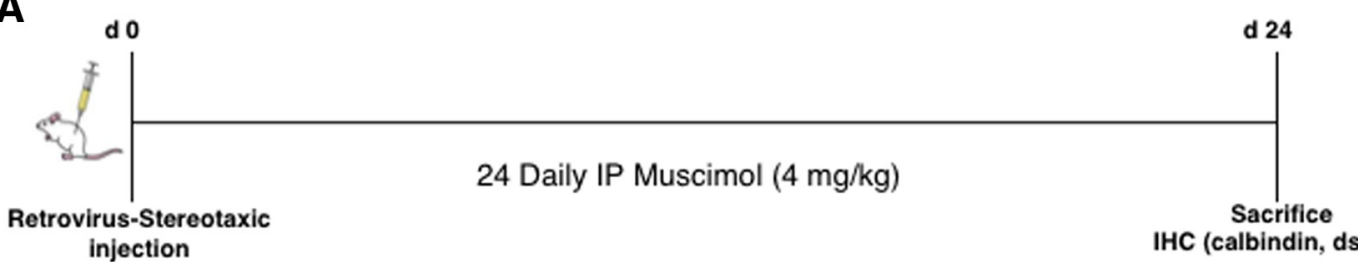

B

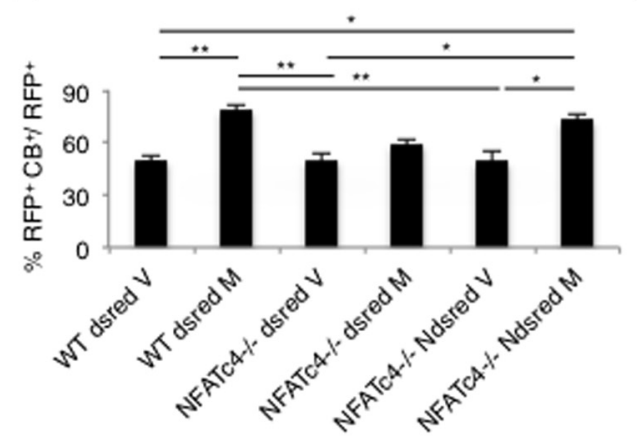

D

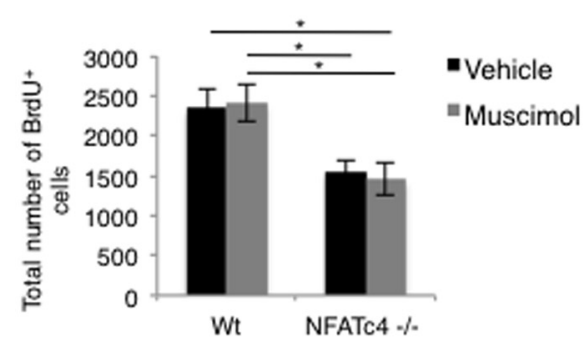

C
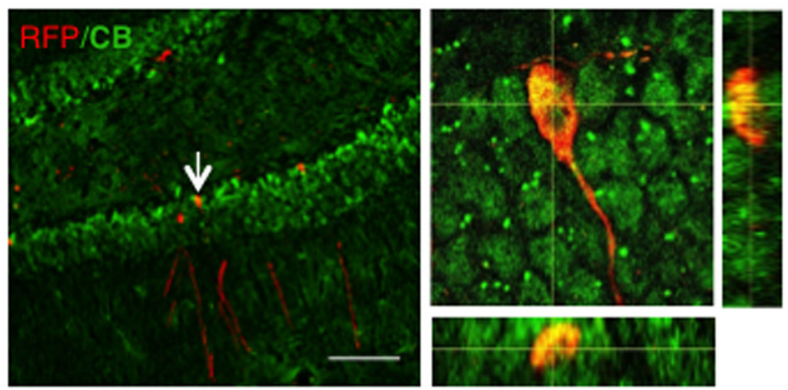

E

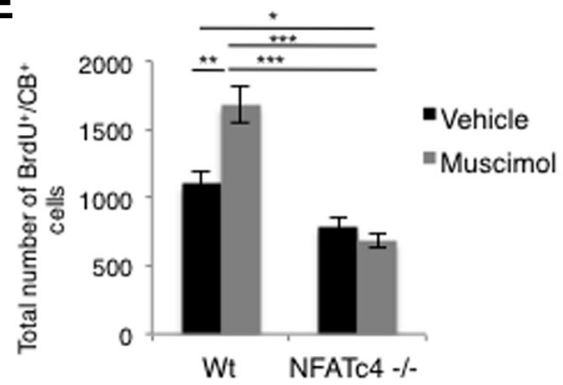

F

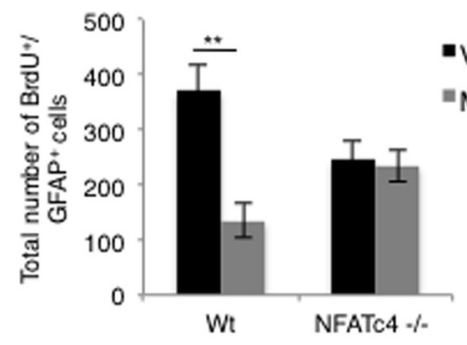

G

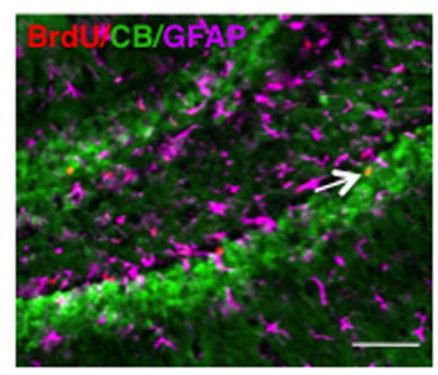

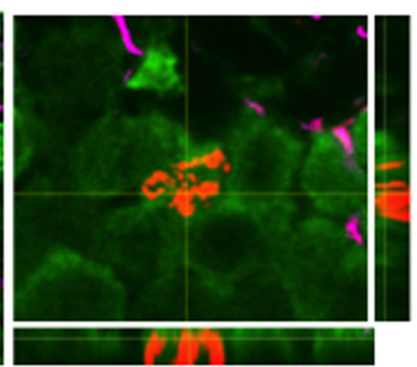

Figure 8. Stimulation of $G A B A_{A} R / N F A T C 4$ axis enhances neural precursor cells differentiation in the adult DG without affecting their survival. $A$, Diagram summarizing the experimental design. $B$, Quantification of the percentage of RFP ${ }^{+}$cells differentiated into mature $\mathrm{CB}^{+}$neurons in the DG of WT and NFATC4 ${ }^{-1-}$ mice injected with control (dsred) or NFATc4-expressing retrovirus (Ndsred) after chronic treatment with muscimol ( $4 \mathrm{mg} / \mathrm{kg}$ ) or vehicle. Data are shown as mean $\pm \mathrm{SEM} ; n=4$; one-way ANOVA followed by Bonferroni post hoc test: ${ }^{*} p<0.05$; ${ }^{* *} p<0.01$. C, Left, Confocal image of adult hippocampal mouse section stereotaxically injected with NFATc4 dsred-expressing retrovirus (red) showing colocalization with (B (green). Scale bar, $100 \mu \mathrm{m}$. Right, Higher magnification of the image with z-axis projection showing colocalization of retroviral infection (red) and CB expression (green) in the three projections. Quantification of the total number of BrdU ${ }^{+}$ cells $(\boldsymbol{D}), \mathrm{BrdU}^{+} / \mathrm{CB}^{+}$cells $(\boldsymbol{E})$, and BrdU ${ }^{+} / \mathrm{GFAP}^{+}$cells $(\boldsymbol{F})$ in the entire DG of WT and NFATc4 ${ }^{-/-}$mice after treatment with either muscimol or vehicle for $24 \mathrm{~d}$. BrdU (red; $75 \mathrm{mg} / \mathrm{kg}$ ) was injected twice daily for $3 \mathrm{~d}$ at the beginning of the muscimol injection. Data are shown as mean \pm SEM; $n=5$; one-way ANOVA followed by Bonferroni posthoc test: ${ }^{*} p<0.05$; ${ }^{* *} p<0.01$; ${ }^{* * *} p<0.001$. $G$, Left, Confocal image of adult hippocampal mouse section after injection of muscimol for $24 \mathrm{~d}$. The image shows colocalization of BrdU (red) with CB (green) but not with GFAP (violet). Scale bar, $100 \mu \mathrm{m}$. BrdU (75 mg/kg) was injected twice daily for $3 \mathrm{~d}$ at the beginning of the muscimol injection. Right, Higher magnification of the image with z-axis projection showing colocalization of BrdU (red) and CB expression (green) in the three projections.

ablated adult neurogenesis in mice after $\mathrm{GABA}_{\mathrm{A}} \mathrm{R}$ stimulation by using the DNA-alkylating agent temozolomide (TMZ), as described previously (Garthe et al., 2009). We subjected the mice injected with muscimol or vehicle to treatment with TMZ (25 $\mathrm{mg} / \mathrm{kg}$ ) for $3 \mathrm{~d}$ every week for 4 weeks (Fig. 9A). After chronic administration of both muscimol and TMZ, we did not observe any weight loss or behavioral abnormality. To confirm the suppression of neurogenesis after TMZ treatment, BrdU $(75 \mathrm{mg} / \mathrm{kg})$ was injected for the first $3 \mathrm{~d}$ twice per day and BrdU staining was performed 4 weeks after injection. Consistent with previous data by Garthe et al. (2009), the number of BrdU ${ }^{+}$cells in the DG decreased by $>80 \%$ (Fig. 9) in TMZ-treated mice compared with vehicle. Importantly, we found that, after depletion of the pool of newborn neurons, the anxiolytic effect of muscimol was blocked (mean \pm SEM: WT TMZ, $18.74 \pm 2.67 \%$; WT TMZ muscimol, $30.83 \pm 5.6 \%$; Fig. $9 B, C$ ), suggesting that NFATc4-dependent 
A

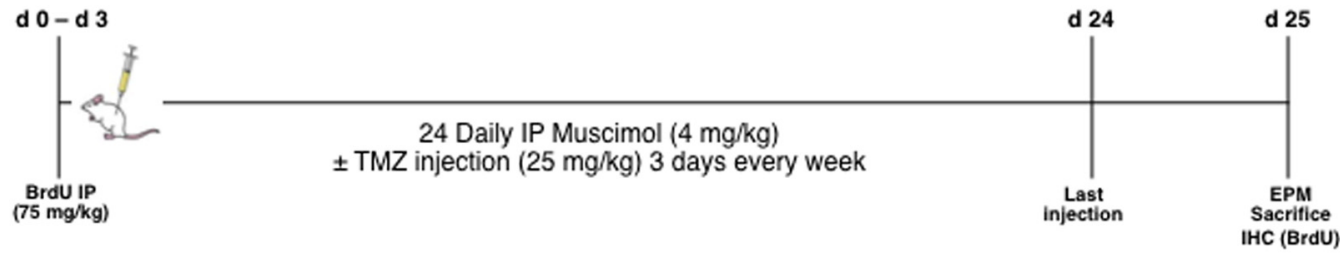

B
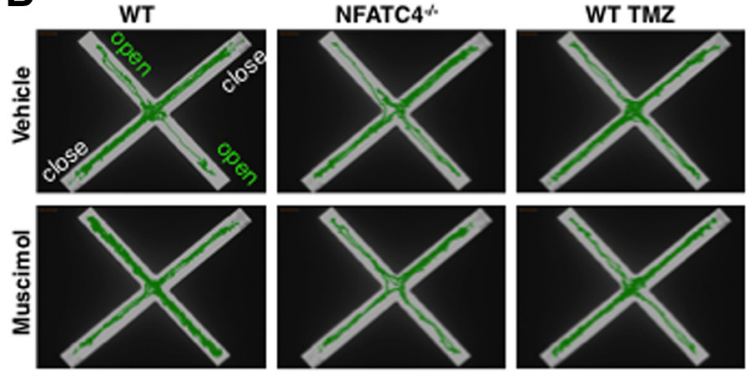

D

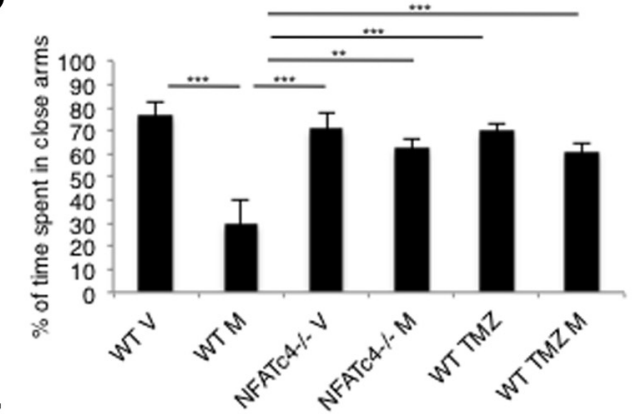

F

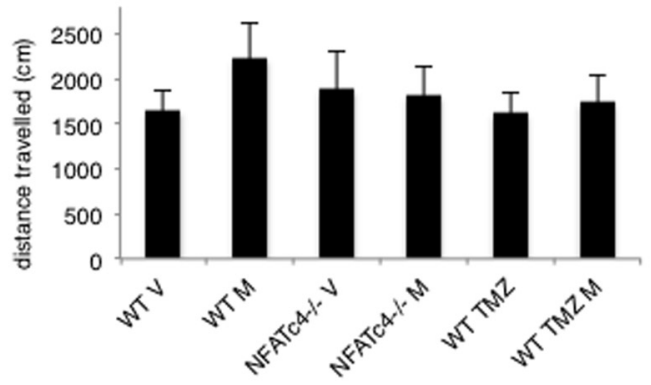

H

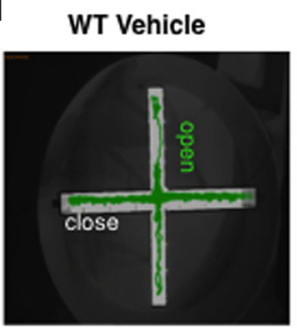

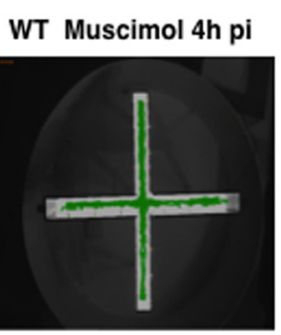

G

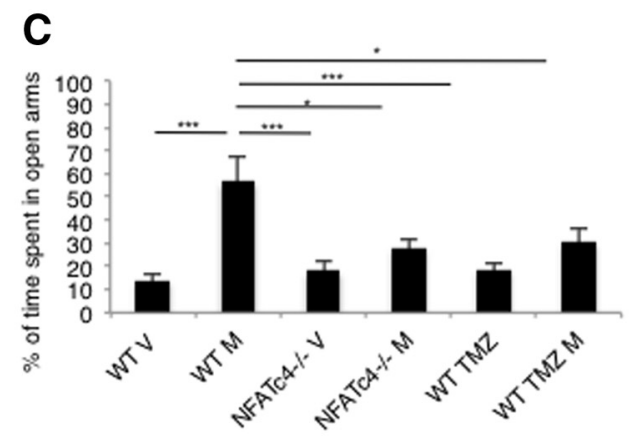

E

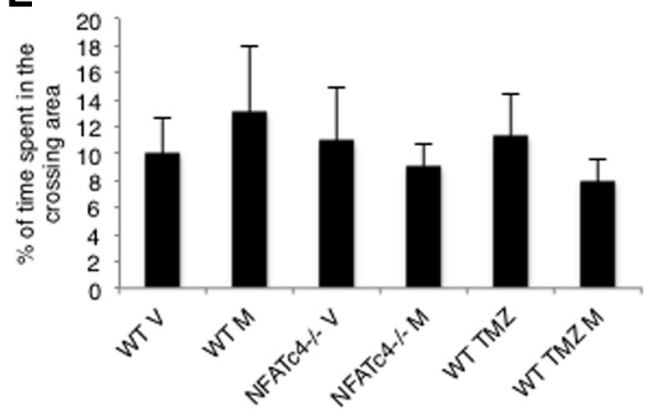

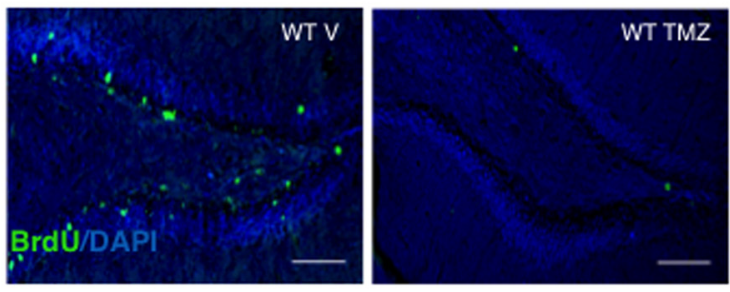

I
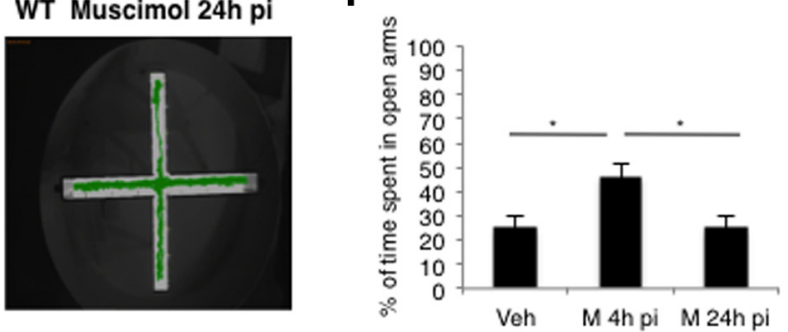

Figure 9. GABAergic signaling regulates innate anxiety by enhancing adult hippocampal neurogenesis via NFATc4. A, Diagram summarizing the experimental design. $\boldsymbol{B}$, Track trace of the path traveled inside the EPM (as a measure of anxiety-related behavior) by adult WT and NFATC $4^{-1-}$ mice injected intraperitoneally with either vehicle or muscimol and adult WT mice injected with TMZ or TMZ + muscimol. Shown is the percentage of time spent in open arms $(\boldsymbol{C})$, the percentage of time spent in the closed arms $(\boldsymbol{D})$, and the percentage of time spent in the crossing area $(\boldsymbol{E})$ of the EPM for each group of mice. $F$, Distance traveled (in centimeters) by each group of mice. Data are shown as mean $\pm \mathrm{SEM} ; n=8-9$; one-way ANOVA followed by Bonferroni post hoc test: ${ }^{*} p<0.05$; ${ }^{* *} p<0.01 ;{ }^{* * *} p<0.001$. G, Immunofluorescence staining BrdU (green) and DAPI (blue) of cells in the DG of adult mice after treatment with either DMSO or TMZ for 4 weeks. BrdU (75 mg/kg) was injected twice daily for $3 \mathrm{~d}$ at the beginning of the TMZ injection. Scale bar, $100 \mu \mathrm{m}$. $\boldsymbol{H}$, Track trace of the path traveled inside the EPM as a measure of anxiety-related behavior by adult mice injected intraperitoneally with either vehicle or muscimol and tested 4 and $24 \mathrm{~h}$ after the injection. $I$, Percentage of time spent in open arms of EPM for each group of mice Data are shown as mean $\pm S E M$; $n=8-9$; one-way ANOVA followed by Bonferroni post hoc test: ${ }^{*} p<0.05$. 
Table 2. List of selected activity-dependent transcription factors dysregulated in NFATC4 ${ }^{-1-}$ versus WT NPCs

\begin{tabular}{|c|c|c|c|}
\hline Transcription factor & Gene symbol & $p$-value & Fold change \\
\hline Transcription factor AP-2, alpha & Tcfap2a & $6.16 \mathrm{E}-05$ & -3.25611 \\
\hline Kruppel-like factor 3 (basic) & KIf3 & 0.0066588 & 1.55157 \\
\hline Kruppel-like factor 7 (ubiquitous) & Klf7 & 0.0065203 & 1.5635 \\
\hline SRY-box containing gene 3 & Sox3 & 0.0211343 & 1.57981 \\
\hline Jun oncogene & Jun & 0.00131103 & 1.6344 \\
\hline Serum response factor & Srf & 0.00168413 & 1.64131 \\
\hline E2F transcription factor 8 & E2f8 & 0.00010667 & 1.6562 \\
\hline $\begin{array}{l}\text { Activity regulated cytoskeletal-associated } \\
\text { protein }\end{array}$ & Arc & 0.00804037 & 2.07333 \\
\hline Kruppel-like factor 10 & Klf10 & 0.00882834 & 2.27326 \\
\hline Early growth response 1 & Egr1 & $6.72 \mathrm{E}-05$ & 2.42541 \\
\hline Kruppel-like factor 4 (gut) & Klf4 & 0.00115389 & 2.52126 \\
\hline Sprouty homolog 1 (Drosophila) & Spry1 & 0.00011628 & 3.09002 \\
\hline Activating transcription factor 3 & Atf3 & 0.0002939 & 2.82386 \\
\hline Early growth response 4 & Egr4 & 0.00129318 & 3.55125 \\
\hline Early growth response 2 & Egr2 & 0.00101158 & 4.85203 \\
\hline Early growth response 3 & Egr3 & 0.001503 & 5.43789 \\
\hline CAMP responsive element binding protein 5 & Creb 5 & $2.83 \mathrm{E}-05$ & 2.1812 \\
\hline Fos-like antigen 2 & Fosl2 & 0.00443229 & 2.08966 \\
\hline $\begin{array}{l}\text { Nuclear factor of kappa light polypeptide } \\
\text { gene enhancer in B-cells }\end{array}$ & Nfkbiz & 0.040712 & 1.71399 \\
\hline
\end{tabular}

Shown is a list of transcription factors dysregulated in NFATc4 ${ }^{-1-}$ differentiating NPCs after genome wide-analysis.

increase in neurogenesis is required for the anxiolytic effect observed in mice after $\mathrm{GABA}_{\mathrm{A}} \mathrm{R}$ stimulation. To demonstrate that the anxiolytic effects observed are consistent with the time course required for neurogenesis, we tested the behavior of the mice in the EPM task 4 and $24 \mathrm{~h}$ after a single dose injection of muscimol. We observed an increase in the time spent in the open arms after $4 \mathrm{~h}$ but, as opposed to chronic administration, the anxyolitic effect of muscimol was not observed at the $24 \mathrm{~h}$ time points (Fig. $9 H, I)$. These data suggest that, although the acute administration of muscimol has an effect on other brain regions, its chronic anxiolytic effect is mediated via increased neurogenesis.

\section{Discussion}

The NFAT (c1-c4) proteins belong to a family of activitydependent transcription factors that transduce and integrate neuronal-activity-driven stimuli in a number of cell types after calcium influx and calcineurin activation (Clipstone and Crabtree, 1992; Rao et al., 1997; Graef et al., 1999; Graef et al., 2003; Crabtree and Schreiber, 2009; Vashishta et al., 2009). Specifically, we recently showed that NFATc4 regulates synaptic plasticity and long-term memory formation in the adult hippocampus by transducing BDNF signaling in hippocampal newborn neurons (Quadrato et al., 2012). Dendritic BDNF regulates activity-dependent hippocampal synaptic plasticity (Waterhouse and $\mathrm{Xu}, 2009)$ by promoting the differentiation of hippocampal adult-born neurons via GABAergic transmission (Waterhouse et al., 2012). These observations suggested that NFATc4 may act as a transcriptional link between changes in neuronal activity and GABAergic signaling in the adult hippocampal neurogenic niche. In support of this hypothesis, here, we have identified GABAergic signaling as a central pathway transcriptionally targeted by NFATc4.

Several studies suggest that gene expression levels of the different subunits of the GABAR change in response to extracellular stimuli (Tseng et al., 1994; Harris et al., 1995). However, despite the fact that GABA is the most important inhibitory transmitters at CNS synapses and that alterations in $\mathrm{GABA}_{\mathrm{A}} \mathrm{R}$ expression levels are implicated in the pathogenesis of several CNS disorders including anxiety (Möhler, 2006), little was known about the transcriptional regulation of the $\mathrm{GABA}_{\mathrm{A}} \mathrm{R}$ subunits.

Our data show that, in the absence of NFATc4, BDNF fails to stimulate the GABRA2 and GABRA4 promoters, leading to downregulation of GABRA2 and GABRA4 gene and protein expression in NPCs. In addition, we found that NFATc4 occupies specific transcriptional binding sites on GABRA2 and GABRA4 promoters and drives their expression, as shown by the ChIP and luciferase assays, respectively. Furthermore, NFATc4 rescue in null NPCs restores GABRA2 and GABRA4 expression levels, further confirming NFATc4 as a major player in the transcriptional machinery regulating $\mathrm{GABRA}_{\mathrm{A}} \mathrm{R}$ expression.

NFAT-mediated transcriptional regulation is orchestrated, in many cases, by the formation of composite regulatory complexes (Macián et al., 2001; Soto-Nieves et al., 2009). Indeed, via genome-wide analysis, we have identified a number of transcription factors dysregulated in NFATc4 ${ }^{-1-}$ NPCs, including the four members of the early growth responsive (EGR) protein fam-

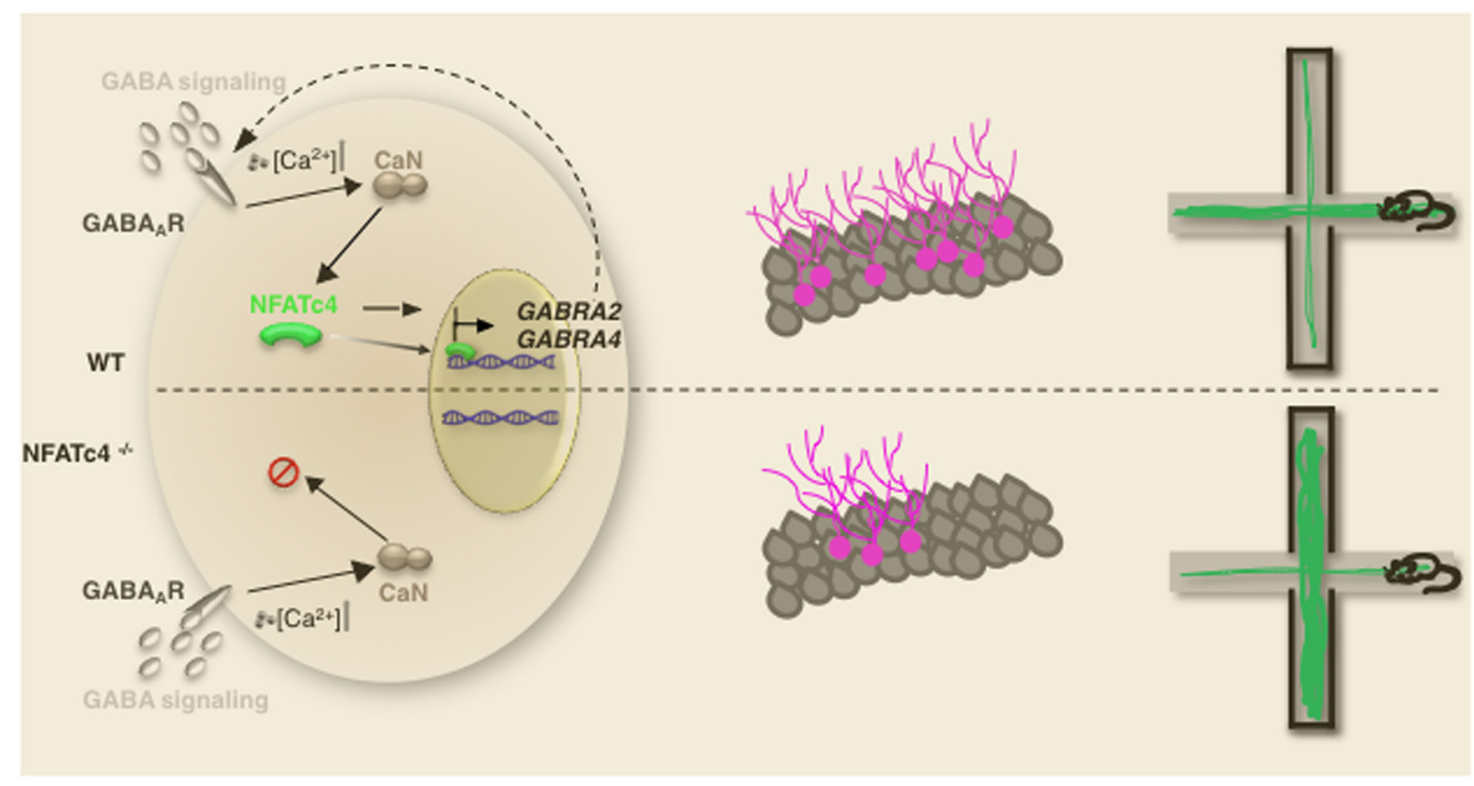

Figure 10. Graphical abstract summarizing the findings. 
ily (Table 2). EGR3 in particular has been shown to regulate GABRA4 expression through direct binding to its promoter after BDNF administration (Roberts et al., 2005). Similarly, through bioinformatics analysis, we have identified single and composite potential responsive elements for NFAT and other activitydependent transcription factors, including EGRs, in the promoter region of the GABRA2 and GABRA4 genes (data not shown). These observations suggest that NFATc4 may control GABAergic signaling transcriptionally in hippocampal NPCs by regulating other activity-dependent transcription factors and by forming composite enhancer complexes on the GABRA2 and GABRA4 genomic cluster.

We also demonstrate here that calcineurin activity is required for NFATc4-dependent regulation of GABRA $\mathrm{A}_{\mathrm{A}} \mathrm{R}$ in hippocampal NPCs. Indeed, CsA-mediated inhibition of calcineurin activity blocks NFATc4 binding to the GABRA2 and GABRA4 promoters and leads to a decrease in their expression, phenocopying NFATc4 absence.

The major cellular event that leads to calcineurin activation is an increase in intracellular calcium (Rusnak and Mertz, 2000). It is known that GABAergic depolarization enhances $\mathrm{Ca}^{2+}$ levels, mainly via activation of $\mathrm{Ca}^{2+}$ channels and via release of $\mathrm{Ca}^{2+}$ from internal stores (Ge et al., 2007; Young et al., 2010). Along the same lines, in our study, we show that enhancement of GABAergic transmission in NPCs leads to increases in NFATc4 transcriptional activity via calcineurin activation.

GABAergic depolarization after the administration of $\mathrm{GABA}_{\mathrm{A}} \mathrm{R}$ agonists increases $\mathrm{Ca}^{2+}$ levels in hippocampal neural progenitor cells, promoting activity-dependent neuronal differentiation (Tozuka et al., 2005; Ge et al., 2006). These findings are consistent with the present study, in which we found that administration of a selective agonist of $\mathrm{GABA}_{\mathrm{A}} \mathrm{R}$ increases the percentage of new neurons generated from hippocampal progenitor cells both in vitro and in vivo. The same treatment did not produce any effect in NFATc4 ${ }^{-/-}$mice, but, importantly, selective NFATc4 rescue of function in hippocampal NPCs derived from null mice restores neuronal differentiation to the WT level after muscimol administration. Interestingly, we have shown that the $\mathrm{GABA}_{\mathrm{A}} \mathrm{R} /$ NFATc4 axis is selectively active in a subpopulation of early neural stem/progenitor cells, suggesting a transient effect of NFATc4. Indeed, the nuclear translocation of NFATc 4 induced by GABAergic excitation occurs only in a restricted time frame that is critical for neural stem/progenitor cells fate choice. These data suggest a major role for NFATc4 in promoting neuronal differentiation in adult hippocampal progenitor cells after GABAergic excitation.

In the last several years, there has been speculation about the role of adult-born hippocampal neurons in the regulation of cognitive and emotional response. Although the hypothesis that a decrease in hippocampal neurogenesis per se might result in depression or anxiety has generally been rejected (Petrik et al., 2012), increasing evidence suggests that adult-born neurons play an important role in both discrimination of similar memory traces (pattern separation; Aimone et al., 2006; Dupret et al., 2008; Clelland et al., 2009; Deng et al., 2010; Sahay et al., 2011) and in buffering stress and depressive behavior (Snyder et al., 2011). Specifically, the current standing of the neurogenesis hypothesis on emotional and depressive disorders infers that the treatment of anxiety/depression-related behavior in mice requires intact hippocampal neurogenesis (Santarelli et al., 2003; David et al., 2009; Surget et al., 2011). Furthermore, increases in adult neurogenesis after physiological stimuli that drive changes in neuronal activity, including exposure to enriched environ- ment and running, is associated with a rescue of anxiety-like phenotype (Schloesser et al., 2010; Onksen et al., 2012).

Similarly, we found that increased chronic GABAergic excitation decreases the anxiety response in WT mice, but not in in NFATc $4^{-1-}$ mice, in which the hippocampal neurogenic response is impaired. Importantly, TMZ-dependent ablation of neurogenesis phenocopied NFATc $4^{-l-}$ mice, further suggesting that an increase in adult hippocampal neurogenesis is required for the anxiolytic effect of $\mathrm{GABA}_{\mathrm{A}} \mathrm{R}$ stimulation. Although our data demonstrate the essential role of hippocampal adult-born neurons in controlling anxiety, future studies are needed to elucidate the crosstalk between adult hippocampal neurogenesis and the function of other well characterized limbic structures involved in the anxiety response.

In summary, we have identified a positive excitatory feedback loop between GABAergic signaling and NFATc4 in which stimulation of $\mathrm{GABA}_{\mathrm{A}} \mathrm{R}$ raises calcineurin/NFATc4 transcriptional activity, leading to increased adult hippocampal neurogenesis (Fig. 10A). These results provide novel functional and molecular insights into the regulation of anxiety, thus highlighting the therapeutic potential of the modulation of adult hippocampal neurogenesis via the $\mathrm{GABA}_{\mathrm{A}} \mathrm{R} / \mathrm{NFATc} 4$ axis in emotional disorders.

\section{References}

Aimone JB, Wiles J, Gage FH (2006) Potential role for adult neurogenesis in the encoding of time in new memories. Nat Neurosci 9:723-727. CrossRef Medline

Campbell S, Marriott M, Nahmias C, MacQueen GM (2004) Lower hippocampal volume in patients suffering from depression: a meta-analysis. Am J Psychiatry 161:598-607. CrossRef Medline

Clelland CD, Choi M, Romberg C, Clemenson GD Jr, Fragniere A, Tyers P, Jessberger S, Saksida LM, Barker RA, Gage FH, Bussey TJ (2009) A functional role for adult hippocampal neurogenesis in spatial pattern separation. Science 325:210-213. CrossRef Medline

Clipstone NA, Crabtree GR (1992) Identification of calcineurin as a key signalling enzyme in T-lymphocyte activation. Nature 357:695-697. CrossRef Medline

Crabtree GR, Schreiber SL (2009) SnapShot: Ca2+-calcineurin-NFAT signaling. Cell 138:210, 210 e211. CrossRef Medline

David DJ, Samuels BA, Rainer Q, Wang JW, Marsteller D, Mendez I, Drew M, Craig DA, Guiard BP, Guilloux JP, Artymyshyn RP, Gardier AM, Gerald C, Antonijevic IA, Leonardo ED, Hen R (2009) Neurogenesisdependent and -independent effects of fluoxetine in an animal model of anxiety/depression. Neuron 62:479-493. CrossRef Medline

Deng W, Aimone JB, Gage FH (2010) New neurons and new memories: how does adult hippocampal neurogenesis affect learning and memory? Nat Rev Neurosci 11:339-350. CrossRef Medline

Dupret D, Revest JM, Koehl M, Ichas F, De Giorgi F, Costet P, Abrous DN, Piazza PV (2008) Spatial relational memory requires hippocampal adult neurogenesis. PLoS One 3:e1959. CrossRef Medline

Duveau V, Laustela S, Barth L, Gianolini F, Vogt KE, Keist R, Chandra D, Homanics GE, Rudolph U, Fritschy JM (2011) Spatiotemporal specificity of GABAA receptor-mediated regulation of adult hippocampal neurogenesis. Eur J Neurosci 34:362-373. CrossRef Medline

Ferri AL, Cavallaro M, Braida D, Di Cristofano A, Canta A, Vezzani A, Ottolenghi S, Pandolfi PP, Sala M, DeBiasi S, Nicolis SK (2004) Sox2 deficiency causes neurodegeneration and impaired neurogenesis in the adult mouse brain. Development 131:3805-3819. CrossRef Medline

Floriddia E, Nguyen T, Di Giovanni S (2011) Chromatin immunoprecipitation from dorsal root ganglia tissue following axonal injury. J Vis Exp 2011(5):pii:2803. CrossRef Medline

Gao Z, Ure K, Ables JL, Lagace DC, Nave KA, Goebbels S, Eisch AJ, Hsieh J (2009) Neurod1 is essential for the survival and maturation of adultborn neurons. Nat Neurosci 12:1090-1092. CrossRef Medline

Garthe A, Behr J, Kempermann G (2009) Adult-generated hippocampal neurons allow the flexible use of spatially precise learning strategies. PLoS One 4:e5464. CrossRef Medline

Ge S, Goh EL, Sailor KA, Kitabatake Y, Ming GL, Song H (2006) GABA 
regulates synaptic integration of newly generated neurons in the adult brain. Nature 439:589-593. CrossRef Medline

Ge S, Pradhan DA, Ming GL, Song H (2007) GABA sets the tempo for activitydependent adult neurogenesis. Trends Neurosci 30:1-8. CrossRef Medline

Gilbertson MW, Shenton ME, Ciszewski A, Kasai K, Lasko NB, Orr SP, Pitman RK (2002) Smaller hippocampal volume predicts pathologic vulnerability to psychological trauma. Nat Neurosci 5:1242-1247. CrossRef Medline

Graef IA, Mermelstein PG, Stankunas K, Neilson JR, Deisseroth K, Tsien RW, Crabtree GR (1999) L-type calcium channels and GSK-3 regulate the activity of NF-ATc4 in hippocampal neurons. Nature 401:703-708. CrossRef Medline

Graef IA, Wang F, Charron F, Chen L, Neilson J, Tessier-Lavigne M, Crabtree GR (2003) Neurotrophins and netrins require calcineurin/NFAT signaling to stimulate outgrowth of embryonic axons. Cell 113:657-670. CrossRef Medline

Gu Y, Janoschka S, Ge S (2011) Studying the integration of adult-born neurons. J Vis Exp 2011(49):pii:2548. CrossRef Medline

Harris BT, Costa E, Grayson DR (1995) Exposure of neuronal cultures to $\mathrm{K}+$ depolarization or to $\mathrm{N}$-methyl-D-aspartate increases the transcription of genes encoding the alpha 1 and alpha 5 GABAA receptor subunits. Brain Res Mol Brain Res 28:338-342. CrossRef Medline

Hogg S (1996) A review of the validity and variability of the elevated plusmaze as an animal model of anxiety. Pharmacol Biochem Behav 54:21-30. CrossRef Medline

Irle E, Ruhleder M, Lange C, Seidler-Brandler U, Salzer S, Dechent P, Weniger G, Leibing E, Leichsenring F (2010) Reduced amygdalar and hippocampal size in adults with generalized social phobia. J Psychiatry Neurosci 35:126-131. CrossRef Medline

Joyce CJ (2007) In silico comparative genomic analysis of GABAA receptor transcriptional regulation. BMC Genomics 8:203. CrossRef Medline

Kempermann G, Kuhn HG, Gage FH (1997) Genetic influence on neurogenesis in the dentate gyrus of adult mice. Proc Natl Acad Sci U S A 94:10409-10414. CrossRef Medline

Kheirbek MA, Hen R (2013) (Radio)active Neurogenesis in the Human Hippocampus. Cell 153:1183-1184. CrossRef Medline

Kheirbek MA, Klemenhagen KC, Sahay A, Hen R (2012) Neurogenesis and generalization: a new approach to stratify and treat anxiety disorders. Nat Neurosci 15:1613-1620. CrossRef Medline

Kheirbek MA, Drew LJ, Burghardt NS, Costantini DO, Tannenholz L, Ahmari SE, Zeng H, Fenton AA, Hen R (2013) Differential control of learning and anxiety along the dorsoventral axis of the dentate gyrus. Neuron 77:955-968. CrossRef Medline

Kitayama N, Vaccarino V, Kutner M, Weiss P, Bremner JD (2005) Magnetic resonance imaging (MRI) measurement of hippocampal volume in posttraumatic stress disorder: a meta-analysis. J Affect Disord 88:79-86. CrossRef Medline

Lippa A, Czobor P, Stark J, Beer B, Kostakis E, Gravielle M, Bandyopadhyay S, Russek SJ, Gibbs TT, Farb DH, Skolnick P (2005) Selective anxiolysis produced by ocinaplon, a GABA(A) receptor modulator. Proc Natl Acad Sci U S A 102:7380-7385. CrossRef Medline

Lugert S, Basak O, Knuckles P, Haussler U, Fabel K, Götz M, Haas CA, Kempermann G, Taylor V, Giachino C (2010) Quiescent and active hippocampal neural stem cells with distinct morphologies respond selectively to physiological and pathological stimuli and aging. Cell Stem Cell 6:445-456. CrossRef Medline

Lydiard RB (2003) The role of GABA in anxiety disorders. J Clin Psychiatry 64:21-27. Medline

Macián F, López-Rodríguez C, Rao A (2001) Partners in transcription: NFAT and AP-1. Oncogene 20:2476-2489. CrossRef Medline

Möhler H (2006) GABAA receptors in central nervous system disease: anxiety, epilepsy, and insomnia. J Recept Signal Transduct Res 26:731-740. CrossRef Medline

Nemeroff CB (2003) The role of GABA in the pathophysiology and treatment of anxiety disorders. Psychopharmacol Bull 37:133-146. Medline

Onksen JL, Briand LA, Galante RJ, Pack AI, Blendy JA (2012) Runninginduced anxiety is dependent on increases in hippocampal neurogenesis. Genes Brain Behav 11:529-538. CrossRef Medline

Petrik D, Lagace DC, Eisch AJ (2012) The neurogenesis hypothesis of affective and anxiety disorders: are we mistaking the scaffolding for the building? Neuropharmacology 62:21-34. CrossRef Medline

Quadrato G, Benevento M, Alber S, Jacob C, Floriddia EM, Nguyen T, Elnag- gar MY, Pedroarena CM, Molkentin JD, Di Giovanni S (2012) Nuclear factor of activated T cells (NFATc4) is required for BDNF-dependent survival of adult-born neurons and spatial memory formation in the hippocampus. Proc Natl Acad Sci U S A 109:E1499-1508. CrossRef Medline

Rao A, Luo C, Hogan PG (1997) Transcription factors of the NFAT family: regulation and function. Annu Rev Immunol 15:707-747. CrossRef Medline

Roberts DS, Raol YH, Bandyopadhyay S, Lund IV, Budreck EC, Passini MJ, Wolfe JH, Brooks-Kayal AR, Russek SJ (2005) Egr3 stimulation of GABRA4 promoter activity as a mechanism for seizure-induced upregulation of $\mathrm{GABA}(\mathrm{A})$ receptor alpha4 subunit expression. Proc Natl Acad Sci U S A 102:11894-11899. CrossRef Medline

Rusnak F, Mertz P (2000) Calcineurin: form and function. Physiol Rev 80: 1483-1521. Medline

Sahay A, Scobie KN, Hill AS, O'Carroll CM, Kheirbek MA, Burghardt NS, Fenton AA, Dranovsky A, Hen R (2011) Increasing adult hippocampal neurogenesis is sufficient to improve pattern separation. Nature 472:466470. CrossRef Medline

Santarelli L, Saxe M, Gross C, Surget A, Battaglia F, Dulawa S, Weisstaub N, Lee J, Duman R, Arancio O, Belzung C, Hen R (2003) Requirement of hippocampal neurogenesis for the behavioral effects of antidepressants. Science 301:805-809. CrossRef Medline

Schloesser RJ, Lehmann M, Martinowich K, Manji HK, Herkenham M (2010) Environmental enrichment requires adult neurogenesis to facilitate the recovery from psychosocial stress. Mol Psychiatry 15:1152-1163. CrossRef Medline

Shaw KT, Ho AM, Raghavan A, Kim J, Jain J, Park J, Sharma S, Rao A, Hogan PG (1995) Immunosuppressive drugs prevent a rapid dephosphorylation of transcription factor NFAT1 in stimulated immune cells. Proc Natl Acad Sci U S A 92:11205-11209. CrossRef Medline

Snyder JS, Soumier A, Brewer M, Pickel J, Cameron HA (2011) Adult hippocampal neurogenesis buffers stress responses and depressive behaviour. Nature 476:458-461. CrossRef Medline

Soto-Nieves N, Puga I, Abe BT, Bandyopadhyay S, Baine I, Rao A, Macián F (2009) Transcriptional complexes formed by NFAT dimers regulate the induction of T cell tolerance. J Exp Med 206:867-876. CrossRef Medline

Spalding KL, Bergmann O, Alkass K, Bernard S, Salehpour M, Huttner HB, Boström E, Westerlund I, Vial C, Buchholz BA, Possnert G, Mash DC, Druid H, Frisén J (2013) Dynamics of hippocampal neurogenesis in adult humans. Cell 153:1219-1227. CrossRef Medline

Surget A, Tanti A, Leonardo ED, Laugeray A, Rainer Q, Touma C, Palme R, Griebel G, Ibarguen-Vargas Y, Hen R, Belzung C (2011) Antidepressants recruit new neurons to improve stress response regulation. Mol Psychiatry 16:1177-1188. CrossRef Medline

Tozuka Y, Fukuda S, Namba T, Seki T, Hisatsune T (2005) GABAergic excitation promotes neuronal differentiation in adult hippocampal progenitor cells. Neuron 47:803-815. CrossRef Medline

Tseng YT, Wellman SE, Ho IK (1994) In situ hybridization evidence of differential modulation by pentobarbital of GABAA receptor alpha 1- and beta 3-subunit mRNAs. J Neurochem 63:301-309. Medline

Vashishta A, Habas A, Pruunsild P, Zheng JJ, Timmusk T, Hetman M (2009) Nuclear factor of activated T-cells isoform c4 (NFATc4/NFAT3) as a mediator of antiapoptotic transcription in NMDA receptor-stimulated cortical neurons. J Neurosci 29:15331-15340. CrossRef Medline

Waterhouse EG, Xu B (2009) New insights into the role of brain-derived neurotrophic factor in synaptic plasticity. Mol Cell Neurosci 42:81-89. CrossRef Medline

Waterhouse EG, An JJ, Orefice LL, Baydyuk M, Liao GY, Zheng K, Lu B, Xu B (2012) BDNF promotes differentiation and maturation of adult-born neurons through GABAergic transmission. J Neurosci 32:14318-14330. CrossRef Medline

Wilkins BJ, De Windt LJ, Bueno OF, Braz JC, Glascock BJ, Kimball TF, Molkentin JD (2002) Targeted disruption of NFATc3, but not NFATc4, reveals an intrinsic defect in calcineurin-mediated cardiac hypertrophic growth. Mol Cell Biol 22:7603-7613. CrossRef Medline

Young SZ, Platel JC, Nielsen JV, Jensen NA, Bordey A (2010) GABA(A) Increases calcium in subventricular zone astrocyte-like cells through Land T-type voltage-gated calcium channels. Front Cell Neurosci 4:8. CrossRef Medline

Zarrindast M, Rostami P, Sadeghi-Hariri M (2001) GABA(A) but not GABA(B) receptor stimulation induces antianxiety profile in rats. Pharmacol Biochem Behav 69:9-15. CrossRef Medline 